Published in final edited form as:

Chem Res Toxicol. 2016 March 21; 29(3): 367-379. doi:10.1021/acs.chemrestox.5b00513.

\title{
Effects of Twelve Germline Missense Variations on DNA Lesion and G-Quadruplex Bypass Activities of Human DNA Polymerase REV1
}

\author{
Mina Yeom ${ }^{\dagger, \perp}$, In-Hyeok Kim ${ }^{\dagger, \perp}$, Jae-Kwon Kim ${ }^{\dagger}$, KyeongJin Kang ${ }^{\ddagger}$, Robert L. Eoff ${ }^{\S}$, F. Peter \\ Guengerich", and Jeong-Yun Choi ${ }^{\dagger},{ }^{*}$ \\ †Division of Pharmacology, Department of Molecular Cell Biology, Sungkyunkwan University \\ School of Medicine, Suwon, Gyeonggi-do 16419, Republic of Korea \\ ‡Department of Anatomy and Cell Biology, Samsung Biomedical Research Institute, \\ Sungkyunkwan University School of Medicine, Suwon, Gyeonggi-do 16419, Republic of Korea \\ §Department of Biochemistry and Molecular Biology, University of Arkansas for Medical Sciences, \\ Little Rock, Arkansas 72205-7199, United States \\ "Department of Biochemistry, Vanderbilt University School of Medicine, Nashville, Tennessee \\ 37232-0146, United States
}

\section{Abstract}

The Y-family DNA polymerase REV1 is involved in replicative bypass of damaged DNA and Gquadruplex (G4) DNA. In addition to a scaffolding role in the replicative bypass, REV1 acts in a catalytic role as a deoxycytidyl transferase opposite some replication stall sites, e.g. apurinic/ apyrimidinic (AP) sites, $N^{2}$-guanyl lesions, and G4 sites. We characterized the biochemical properties of 12 reported germline missense variants of human REV1, including the N373S variant associated with high risk of cervical cancer, using the recombinant REV1 (residues 330-833) proteins and DNA templates containing a G, AP site, $N^{2}-\mathrm{CH}_{2}$ (2-naphthyl)G ( $N^{2}-\mathrm{NaphG}$ ), or G4. In steady-state kinetic analyses, the F427L, R434Q, M656V, D700N, R704Q, and P831L variants displayed 2- to 8-fold decreases in $k_{\text {cat }} / K_{\mathrm{m}}$ for dCTP insertion opposite all four templates, compared to that of wild-type, while the N373S, M407L, and N497S showed 2- to 3-fold increases with all four and the former three or two templates, respectively. The F427L, R434Q, M656V, and R704Q variants also had 2- to 3-fold lower binding affinities to DNA substrates containing G, an AP site, and/or $N^{2}$-NaphG than wild-type. Distinctively, the N373S variant had a 3-fold higher binding affinity to G4 DNA than wild-type, as well as a 2-fold higher catalytic activity opposite the first tetrad G, suggesting a facilitating effect of this variation on replication of G4 DNA sequences in certain human papillomavirus genomes. Our results suggest that the catalytic

*Address correspondence to: Prof. Jeong-Yun Choi, Division of Pharmacology, Department of Molecular Cell Biology, Samsung Biomedical Research Institute, Sungkyunkwan University School of Medicine, Suwon, Gyeonggi-do 16419, Republic of Korea, Telephone: +82-31-299-6193, FAX: +82-31-299-6209, choijy@ skku.edu.

-M.Y. and I.-H.K. contributed equally to this work.

Supporting Information

Analysis of human REV1 (330-833) wild-type and variant proteins by SDS-polyacrylamide gel electrophoresis (Figure S1). This material is available free of charge via the Internet at http://pubs.acs.org.

The authors declare no competing financial interest. 
function of REV1 is moderately or slightly altered by at least nine genetic variations, and the G4 DNA processing function of REV1 is slightly enhanced by the N373S variation, which might provide the possibility that certain germline missense REV1 variations affect the individual susceptibility to carcinogenesis by modifying the capability of REV1 for replicative bypass past DNA lesions and G4 motifs derived from chemical and viral carcinogens.

\section{Graphical abstract}

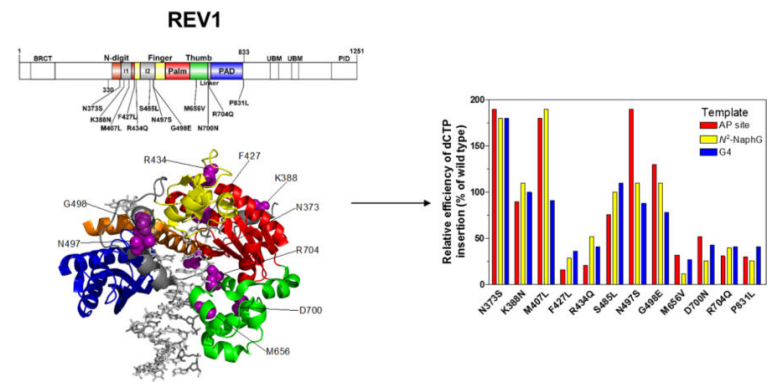

\section{Keywords}

DNA polymerase; REV1; translesion DNA synthesis; carcinogen; DNA lesion; genetic variation

\section{INTRODUCTION}

The accurate maintenance of genomic information is vital for cell homeostasis and survival in living organisms. A major threat to the genome is DNA damage, which is constantly generated in a variety of forms by a plethora of exogenous and endogenous agents. ${ }^{1}$ Damaged DNA can be restored to its original state with sophisticated DNA repair systems, but these systems are not perfect and some lesions persist in cellular DNA. Unrepaired or misrepaired DNA lesions can result in genetic mutations or cell death depending on the type and magnitude of damage, potentially leading to cancer, aging, and other problems. ${ }^{2}$ One set of key players in these processes is the DNA polymerases (pols), which can make copying errors (e.g., base substitutions, deletions, and insertions) or be blocked (e.g., replication fork stalling) at the sites of DNA lesions during cellular DNA replication. ${ }^{3}$ Replicative DNA polymerases are mostly blocked at DNA lesions during DNA replication, although they can occasionally replicate through small DNA lesions but with difficulty and errors. ${ }^{4-8}$ To cope with these replication hurdles, cells utilize specialized DNA polymerases, mainly belonging to the Y-family, which have spacious active sites to accommodate and synthesize past a variety of DNA lesions, in a process called translesion synthesis (TLS). ${ }^{9,} 10$ The consequences of these TLS processes can be either error-free or error-prone depending on the types of the DNA lesion and the individual polymerase. ${ }^{11-13}$ For that reason, each DNA polymerase may play either a protective or mutagenic role opposite each specific lesion during DNA-damage-induced mutagenesis in cells. In this regard, it can be postulated that the functional genetic variations of DNA polymerases could affect the TLS capacity and mutation consequences of DNA damage induced by carcinogens in cells, which might further influence cancer susceptibility in the affected individuals. 
REV1, one member of the eukaryotic Y-polymerase family, has been suggested to play both catalytic and non-catalytic roles in TLS. REV1 has been proposed to act largely as a scaffolding protein that mediates protein-protein interactions with PCNA, ubiquitin, and other polymerases to coordinate TLS process. ${ }^{14-17}$ In addition, REV1 has its own catalytic activity as a deoxycytidyl transferase, unique among polymerases, utilizing a proteintemplate directed mechanism. ${ }^{18,19}$ REV1 preferentially incorporates dCTP opposite template G and a variety of DNA lesions including $N^{2}$-G adducts, $1, N^{6}$-etheno-A, and apurinic/apyrimidinic (AP, abasic) sites. ${ }^{20-23}$ Substantial lines of evidence have suggested that REV1 may play catalytic roles in replicative bypass of AP sites and $N^{2}$-G adducts in yeast cells ${ }^{24,25}$ and in AP site bypass during immunoglobulin gene hypermutation in vertebrate $\mathrm{B}$ cells; ${ }^{26,27}$ thus, those lesions are expected to be the favored or cognate lesion substrates for REV1. In addition, REV1 has been also suggested to be involved in the replication of non-B-form DNA structures such as G-quadruplexes (G4s) and hairpin loops ${ }^{28,} 29$ as well as in the repair of DNA interstrand crosslinks and double strand breaks. ${ }^{30-32}$ To date, no human disease linked to REV1 deficiency has been identified, but two REV1 single nucleotide polymorphisms (SNPs) at codons 257 and 373 have been significantly associated with modified cancer risks, although the specific mechanisms have not been revealed yet. The N373S SNP has been associated with an increased risk of cervical cancer, whereas the F257S SNP has been associated with a decreased risk of cervical cancer, but with an increased risk of lung cancer in heavy smokers. ${ }^{33}, 34$ The mutational signatures found in human cervical cancers are $\mathrm{C}$ to $\mathrm{G}$ and $\mathrm{C}$ to $\mathrm{T}$ mutations, which are supposed to be related to the APOBEC 3 upregulation as an innate immune response to human papilloma virus (HPV) infection. ${ }^{35-37}$ REV1 is believed to mediate the former signature mutations by inserting $\mathrm{C}$ opposite $\mathrm{AP}$ sites formed by the sequential action of APOBEC 3 and UNG enzymes at cytosines in host genomes. ${ }^{38}$ It is also notable that the high-risk HPV types 52 and 58 possess putative G4-forming sequences in their genomes, ${ }^{39}$ and their prevalence is relatively high in African women ${ }^{40}$ as well as in non-Hispanic blacks in the United States, ${ }^{41}$ who have the highest frequency of MAF (29\%) for the N373S REV1 SNP according to 1000 Genomes (http://browser.1000genomes.org). Recent reports also suggest that the V138M REV1 SNP is associated with poor outcomes from cisplatin chemotherapy in malignant mesothelioma and osteosarcoma patients. ${ }^{42,}{ }^{43}$ Under these circumstances, it can be speculated that certain human genetic variations of REV1 might alter the REV1 function related to mutagenesis and thus modify individual risks of mutation and cancer from exposure to carcinogens, as well as individual outcomes of anti-cancer treatment.

The human REV1 gene encodes the REV1 protein consisting of 1251 amino acids. The catalytic core of REV1 is positioned in the middle part (amino acids 330-833) of the molecule, while protein-protein interaction domains (e.g., BRCT, UBM, and PID) are located in the $\mathrm{N}$ - and C-terminal regions. ${ }^{10,19}$ The ternary crystal structure of REV1 catalytic core shows that REV1 has fingers, thumb, and palm, and PAD domains-like other Y-family polymerases - and also possesses the unique N-digit domain to induce the eviction of template $\mathrm{G}$ from the active site and the pairing of incoming dCTP with an arginine. ${ }^{19} \mathrm{At}$ the present time, a total of at least 132 non-synonymous single nucleotide variations (SNVs) of human REV1 gene have been described in dbSNP (http://www.ncbi.nlm.nih.gov/projects/ 
SNP), but the functional effects of these genetic variations have not been characterized yet. In the present study, we investigated the consequences of 12 selected germline SNVs in the human REV1 at a biochemical level, in order to characterize human germline REV1 gene variations that alter the catalytic TLS function of REV1. We focused on two groups of nonsynonymous SNVs located in the catalytic core region of $R E V 1$ gene, which are worthy of investigating in detail in terms of their predicted functional effects and population frequencies. The first group includes seven REV1 SNVs that are expected to exert damaging effects on protein function by in silico prediction tools, e.g. SIFT and/or PolyPhen, ${ }^{44-46}$ as we have previously applied this approach to identify catalytically altered variants of Yfamily pols $\kappa$ and $\iota .{ }^{47,48}$ The second group consists of five REV1 SNVs that are predicted to have non-damaging effects, including a common polymorphism (N373S) associated with cervical cancer risk. ${ }^{33}$ We performed the experiments with "standing-start" primer extensions, steady-state kinetics of nucleotide incorporation, and pol-DNA binding, using the recombinant catalytic core (residues 330-833) proteins of wild-type REV1 and 12 variants with primer-annealed oligonucleotide DNA templates containing an undamaged $\mathrm{G}$, AP site, $N^{2}-\mathrm{CH}_{2}$ (2-naphthyl)(Naph)G, or a parallel-stranded intramolecular G4 structure. Here we describe nine germline REV1 SNVs that can decrease or increase in vitro catalytic function of REV1 for dCMP insertion opposite lesion and/or G4 DNA substrates, some of which also alter the DNA binding affinity. These findings are discussed in the context of the potential mechanistic and mutagenic consequences of altered catalytic function with REV1 variants.

\section{EXPERIMENTAL PROCEDURES}

\section{Materials}

The QuickChange mutagenesis kit was obtained from Stratagene (La Jolla, CA). Protease inhibitor cocktail tablets were purchased from Roche Life Science (Indianapolis, IN). FPLC columns and Prescission protease were from GE Healthcare (Uppsala, Sweden). Unlabeled dNTPs and T4 polynucleotide kinase were purchased from New England Biolabs (Ipswich, MA). $\left[\gamma^{-}{ }^{32} \mathrm{P}\right]$ ATP (specific activity $3 \times 10^{3} \mathrm{Ci} / \mathrm{mmol}$ ) was obtained from PerkinElmer Life Sciences (Boston, MA). Micro Bio-Spin columns were purchased from Bio-Rad (Hercules, CA).

\section{Oligonucleotides}

An 11-mer (5'-ATC CTC CCC TA-3'), a 23-mer (5'-GCC TCG AGC CAG CCG CAG ACG CA-3'), a 24-mer ( $5^{\prime}$-GCC TCG AGC CAG CCG CAG ACG CAG-3'), an 18-FAMmer $\left(5^{\prime}\right.$ - (FAM)-AGC CAG CCG CAG ACG CAG-3'; FAM = 6-carboxyfluorescein), a 28G4-FAM-mer ( $5^{\prime}$-(FAM)-TGG GTG GGT AGG GTG GGT AGG GGA GGA T-3'), a 42 G-quadruplex(G4)-mer (5'-TGA GGG TGG GTA GGG TGG GTG CGT CTG CGG CTG GCT CGA GGC-3'), and two 36-mer oligonucleotides (5'-TCG GCG TCC TCX CTG CGT CTG CGG CTG GCT CGA GGC-3'; X = G, or AP site (tetrahydrofuran)) containing a G or AP site (Figure 1) were obtained from Bioneer (Daejeon, Korea). A 36-mer oligonucleotide $\left(\mathrm{X}=N^{2}-\mathrm{CH}_{2}\right.$ (2-naphthyl)G $\left(N^{2}\right.$-NaphG)) containing a $N^{2}$-NaphG (Fig. 1) was prepared as previously described. ${ }^{8}$ Primers were $5^{\prime}$ end-labeled using T4 polynucleotide kinase with $\left[\gamma_{-}{ }^{32} \mathrm{P}\right] \mathrm{ATP}$ and annealed with template in $50 \mathrm{mM}$ HEPES- 
$\mathrm{NaOH}$ (pH 7.5) buffer to make four kinds of duplex primer-template DNA substrates: a 24mer/36-G-mer, a 24-mer/36- $N^{2}$-NaphG-mer, a 24-mer/36-AP-mer, and a 23-mer/42-G4-mer. $\mathrm{KCl}(100 \mathrm{mM})$ was included in the annealing buffer for the G4 DNA substrate (23-mer/42G4-mer).

\section{Selection of Human REV1 Gene Variations to Study}

We made an effort to select natural human $R E V 1$ gene variations that deserve attention for detailed experimental studies. First, we screened for naturally occurring germline REV1 gene variations that are expected to change REV1 catalytic function on the basis of three criteria: i) non-synonymous coding SNVs, ii) SNVs located in the polymerase core domain (amino acid residues 330 to 833), and iii) SNVs predicted to have damaging effects on protein function by SIFT and/or Polyphen programs, ${ }^{44-46}$ from the public database dbSNP (http://www.ncbi.nlm.nih.gov/projects/SNP/). Thus, we chose seven SNVs. Secondly, we selected five additional SNVs that result in missense coding changes but are predicted to have tolerated or non-damaging effects on protein function by prediction programs, some of which are found at relatively high population frequencies. Hence, a common SNP (N373S; minor allele frequency $(\mathrm{MAF})=17 \%$ ) associated with cervical cancer risk, ${ }^{33}$ and a SNV (R704Q, MAF $=0.7 \%$ ) that was also observed in a colon cancer sample from the COSMIC database (http://www.sanger.ac.uk/genetics/CGP/cosmic/) were included for this study. Current information for the $12 R E V 1$ gene variations investigated in this study is summarized in Table 1, based on publically available variant databases such as dbSNP and 1000 Genomes (http://browser.1000genomes.org).

\section{Construction of Expression Vectors for Catalytic Core Proteins of Wild-Type and REV1 variants}

The pBG101-wtREV1 $1330-833$ vector, which encodes the catalytic core protein (amino acids 330-833) having a cleavable N-terminal 6His-GST tag, was prepared using the pBG101 vector (kindly provided by the Vanderbilt Structural Biology Core). Each of the 12 different mutations in the $R E V 1$ gene was created using a QuickChange mutagenesis kit with the pBG101-wtREV1 $1330-833$ vector as template. The oligonucleotide primers for introducing the point mutation in REV1 were 5'-GTG TGA ATT GAC TGA GTT TGT CAG TAC CCT ACA AAG ACA AAG TAA TG-3' for N373S, 5'-GGT ATC TTT CCA GGA AGG GAA AAT TTA AAA AAA ATG AAA ACA GGC AG-3' for K388N, 5'-GTT GTA ACT GAC ACA GGA GAT CTG TCA GTA TTG AAT TCT CC-3' for M407L, 5'-ATG CAT GTT GAT ATG GAT TGC CTC TTT GTA TCA GTG GGT ATA C-3' for F427L, 5'-TCT TTG TAT CAG TGG GTA TAC AAA ATA GAC CAG ATC TCA AAG G-3' for R434Q, 5'-GCA GCA GAT ATA CCA GAT TTA TCA TTG TGG GAG AAT CC-3' for S485L, 5'-GAA TCC AGA TTC TGC GCA AGC AAG TGG AAT TGA TTC TGT TT-3' for N497S, 5'-CAG ATT CTG CGC AAG CAA ATG AAA TTG ATT CTG TTT TGT CAA G-3' for G498E, 5'-CCA ATC TAC CAG GAG TTG GAC ATT CAG TGG AAT CTA AGT TG-3' for M656V, 5'-CTG CCG TGG CTT GGA TAA TAG ACC AGT TCG AAC-3' for D700N, 5'-GCT TGG ATG ATA GAC CAG TTC AAA CTG AAA AGG AAA GAA AAT C-3' for R704Q, 5'-TCC AAC TAA TCT GAA CCT TTC CAC ATA AGC GGC CG-3' for P831L and its corresponding antiparallel primer for each mutation. All 12 variations were confirmed by nucleotide sequence analysis of the constructed expression vectors. 


\section{Expression and Purification of Recombinant REV1 Proteins}

The wild-type and variant forms of recombinant REV1 core proteins were expressed in Escherichia coli strain BL21(DE3) cells. E. coli cells harboring each vector for the recombinant protein were grown in Luria-Bertani (LB) broth supplemented with kanamycin $\left(50 \mu \mathrm{g} \mathrm{mL}{ }^{-1}\right)$ at $37^{\circ} \mathrm{C}$ and $250 \mathrm{rpm}$, with aeration, to an O.D. 600 of 0.5-0.6. Isopropyl- $\beta$ D-1-thiogalactopyranoside was added to $0.2 \mathrm{mM}$, and incubation was continued for $14 \mathrm{~h}$ at $16{ }^{\circ} \mathrm{C}$. The harvested cell pellets were resuspended in lysis buffer $(50 \mathrm{mM}$ Tris- $\mathrm{HCl}, \mathrm{pH} 7.4$, containing $500 \mathrm{mM} \mathrm{NaCl}, 10 \%$ glycerol (v/v), $5 \mathrm{mM} \beta$-mercaptoethanol, $1 \mathrm{mg}$ lysozyme $\mathrm{mL}^{-1}$, and a protease inhibitor cocktail) and cooled on ice for $30 \mathrm{~min}$, and then the suspension was sonicated $(60 \times 2 \mathrm{~s}$ duration with a Branson digital sonifier microtip, (VWR, West Chester, PA), 35\% amplitude, with intermittent cooling time). Lysates were clarified by centrifugation at $4 \times 10^{4} \times g$ for $2 \mathrm{~h}$ at $4{ }^{\circ} \mathrm{C}$. The resulting supernatant was loaded onto a 1$\mathrm{mL}$ GSTrap 4B column and the column was washed with $15 \mathrm{~mL}$ of Buffer A (50 mM Tris$\mathrm{HCl}(\mathrm{pH} 7.4), 150 \mathrm{mM} \mathrm{NaCl}, 0.5 \mathrm{mM}$ EDTA, $10 \%$ glycerol (v/v), and $5 \mathrm{mM} \beta$ mercaptoethanol). The recombinant REV1 core proteins bound on the column were cleaved with Prescission protease for $16 \mathrm{~h}$ at $4{ }^{\circ} \mathrm{C}$. Cleaved recombinant REV1 core proteins were eluted with Buffer A, and diluted 3-fold with Buffer B (50 mM Tris- $\mathrm{HCl}$ (pH 7.4), $1 \mathrm{mM}$ EDTA, $10 \%$ glycerol (v/v), and $5 \mathrm{mM} \beta$-mercaptoethanol). The REV1 core proteins were further purified to near homogeneity with the use of a Mono $S$ column using a $50 \mathrm{mM}$ to 2 $\mathrm{M} \mathrm{NaCl}$ gradient in Buffer B. The REV1 core proteins were eluted at $\sim 400 \mathrm{mM} \mathrm{NaCl}$. The purified proteins were stored at $-80{ }^{\circ} \mathrm{C}$ in $50 \mathrm{mM}$ HEPES-NaOH (pH 7.5) buffer containing $100 \mathrm{mM} \mathrm{NaCl}, 1 \mathrm{mM}$ dithiothreitol, and 50\% glycerol (v/v) after dialysis. The protein concentration was determined using a calculated $\mu_{280}$ value of $34 \mathrm{mM}^{-1} \mathrm{~cm}^{-1}$ for REV1 core protein (http://web.expasy.org/protparam/), and the quality of purified proteins was assessed by SDS-polyacrylamide gel electrophoresis (Figure S1, Supporting Information).

\section{DNA Polymerase Assays and Steady-State Kinetic Analysis}

Standard DNA polymerase reactions of $8 \mu \mathrm{L}$ were performed in $50 \mathrm{mM}$ HEPES-NaOH $(\mathrm{pH}$ 7.5) buffer containing $50 \mathrm{mM} \mathrm{NaCl}, 5 \mathrm{mM}$ dithiothreitol, $100 \mu \mathrm{g} \mathrm{mL}{ }^{-1} \mathrm{BSA}(\mathrm{w} / \mathrm{v}$ ), and $10 \%$ glycerol (v/v) with $100 \mathrm{nM}$ primer-template substrate at $37^{\circ} \mathrm{C}$. Reactions were started by addition of dNTPs and $\mathrm{MgCl}_{2}$ (5 $\mathrm{mM}$ final concentration) to preincubated enzyme/DNA mixtures and quenched by the addition of 12 volumes of a solution of $20 \mathrm{mM}$ EDTA in 95\% formamide $(\mathrm{v} / \mathrm{v}) . \mathrm{KCl}(100 \mathrm{mM})$ instead of $\mathrm{NaCl}(50 \mathrm{mM})$ was included in the reaction buffer for the G4 DNA substrate, in order to stabilize G4 structures. For steady-state kinetic analysis, the primer-template was extended in the presence of 0.1-10 nM REV1 with increasing concentrations of individual dNTPs for 5 or $10 \mathrm{~min}$, where the maximum amount of extension products was $20 \%$ of the total DNA substrate. Products were separated by electrophoresis on a $16 \%$ polyacrylamide $(\mathrm{w} / \mathrm{v}) / 8 \mathrm{M}$ urea gel, and visualized and quantitated with a Personal Molecular Imager and Quantity One software (Bio-Rad). The rate of product formation was plotted as a function of dNTP concentration and fit to the Michaelis-Menten equation using the Prism software (GraphPad, San Diego, CA) to estimate the steady-state kinetic parameters $k_{\text {cat }}$ and $K_{\mathrm{m}}$. 


\section{Fluorescence Polarization Assays}

Four different DNA substrates containing a G, an AP site, $N^{2}$-NaphG, or G4 were prepared for DNA binding assays. The ( $5^{\prime}$ FAM) 18 -mer primer was annealed with the 36-mer template containing G, AP site, or $N^{2}$-NaphG for normal and lesion-containing DNA substrates, while the 11-mer primer was annealed with the (5'FAM) 28-G4-mer template for the G4 DNA substrate. DNA substrates $(2 \mathrm{nM})$ were incubated with varying concentrations of REV1, and fluorescence polarization was measured with a Biotek Synergy NEO plate reader (Winooski, VT) using 485 and $528 \mathrm{~nm}$ excitation and emission filters, respectively. The polymerase-DNA binding reaction was done in the presence of $50 \mathrm{mM}$ HEPES-NaOH buffer ( $\mathrm{pH} 7.5$ ) containing $10 \mathrm{mM}$ potassium acetate, $10 \mathrm{mM} \mathrm{KCl}, 5 \mathrm{mM} \mathrm{MgCl}_{2}, 0.1 \mathrm{mM}$ EDTA, $2 \mathrm{mM} \beta$-mercaptoethanol, and $0.1 \mathrm{mg} \mathrm{mL}^{-1} \mathrm{BSA}$. $\mathrm{KCl}$ was included at $100 \mathrm{mM}$ in the binding buffer for the G4 DNA substrate. The fluorescence polarization data were plotted against the enzyme concentration and fit to a quadratic equation to estimate $K_{\mathrm{d}, \mathrm{DNA}}$ using the equation: $\mathrm{P}=\mathrm{P}_{0}+\left(\mathrm{P}_{\max }-\mathrm{P}_{0}\right)\left(\left(\mathrm{D}_{\mathrm{t}}+\mathrm{E}_{\mathrm{t}}+K_{\mathrm{d}, \mathrm{DNA}}\right)-\left(\left(\mathrm{D}_{\mathrm{t}}+\mathrm{E}_{\mathrm{t}}+K_{\mathrm{d}, \mathrm{DNA}}\right)^{2}\right.\right.$ $\left.\left.-\left(4 \mathrm{D}_{\mathrm{t}} \mathrm{E}_{\mathrm{t}}\right)\right)^{1 / 2}\right) /\left(2 \mathrm{D}_{\mathrm{t}}\right)$, where $\mathrm{P}$ is the observed change in fluorescence polarization, $\mathrm{P}_{0}$ is the initial polarization (DNA alone), $\mathrm{P}_{\max }$ is the maximum polarization, $\mathrm{D}_{\mathrm{t}}$ is the total DNA concentration, $\mathrm{E}_{\mathrm{t}}$ is the total enzyme concentration, and $K_{\mathrm{d}, \mathrm{DNA}}$ is the equilibrium dissociation constant for enzyme binding to DNA.

\section{RESULTS}

\section{Overall Experimental Strategy}

The main goal of this study was to evaluate the biochemical impacts of 12 selected germline genetic variations of human REV1 on its catalytic activity and thus to identify potentially functional human $R E V 1$ gene variations that alter the enzymatic function of REV1. To accomplish this, we focused on the non-synonymous genetic variations located in the catalytic core region (amino acids 330-833) of REV1 from the dbSNP database. We chose $R E V 1$ gene variation candidates that we believe are worthy of attention in aspects of the functional prediction and their population frequency. Here we included two groups of $R E V I$ SNVs for this study, not only ones that have putatively damaging effects but also ones that have putatively non-damaging effects on protein function from in silico prediction by PolyPhen and/or SIFT, in that a considerable number (31\%) of false negative errors has been reported with SIFT and PolyPhen tools. ${ }^{49}$ Thus, the N373S SNP (MAF 16.8\%), which is predicted to be non-damaging but is associated with a cervical cancer risk, was included for this study. The 12 selected SNVs (Table 1 and Figure 2) have some information about the minor allele frequencies (MAFs) estimated in human populations, although the majority are rare and thus could play impacts on a certain subset of people carrying these variants if functional. A series of experiments-including "standing-start" primer extensions, steadystate kinetics of nucleotide incorporation opposite templates, and DNA binding assayswere conducted using the recombinant REV1 core enzymes and oligonucleotides containing a normal G, G4, or each of two bypassable DNA lesions, i.e., an AP site and $N^{2}$-NaphG, to identify the germline SNVs that affect the biochemical properties of REV1 related to the lesion and G4-DNA bypasses. 


\section{Primer Extension at G, AP Site, and $N^{2}$-NaphG by the Wild-Type and Variant REV1 Enzymes}

In order to identify the possible alterations in DNA synthesis activities by 12 REV1 variants compared to wild-type, we extended the 24-mer primers annealed to 36-mer templates containing unmodified G, an AP site, or $N^{2}$-NaphG (Figure 1) at the 25th position in the presence of all four dNTPs using the wild-type and 12 naturally-occurring variant REV1 core proteins (Figure 3). In this study, we utilized two DNA lesion substrates, a noninstructional AP site and a bulky minor-groove $N^{2}-\mathrm{G}$ adduct, which are possibly cognate or highly-favored substrates for REV1. ${ }^{18,20,50,51} N^{2}$-NaphG was chosen as a model bulky $N^{2}$ $\mathrm{G}$ adduct, in that human REV1 bypasses this adduct with efficiency and accuracy comparable to those observed for unmodified G. ${ }^{20}$ Wild-type REV1 extended the primers across $\mathrm{G}$ in proportion to enzyme concentration to yield one- and two-base extended products opposite $\mathrm{G}$ and the subsequent $\mathrm{C}$ (i.e. 25-mers and 26-mers), while generating only one-base extended 25-mer products opposite an AP site or $N^{2}$-NaphG. Although the extents of the extension products by the variants were not greatly different from that for the wildtype, some alterations could be observed in particular variants. The F427L, R434Q, M656V, D700N, R704Q, and P831L variants showed somewhat less extension products past G, an AP site, and/or $N^{2}$-NaphG than the wild-type, while the N373S, M407L, and N497S variants showed slightly more extension products at unmodified G, AP site, and/or $N^{2}$-NaphG than the wild-type, indicating the necessity of the detailed kinetic quantitation of enzyme activities to confirm the alterations in TLS activities due to amino acid substitutions. To further evaluate the difference in enzyme activity between wild-type and variant REV1 proteins, we measured their deoxycytidyl transferase activities incorporating dCTP opposite template G, an AP site, and $N^{2}$-NaphG by performing primer extension assays using low concentrations of only dCTP as described in Figure 4. The comparative graph for deoxycytidyl transferase activities for wild-type and variant REV1 enzymes is presented (Figure 4). The F427L, R434Q, M656V, D700N, R704Q, and P831L variants exhibited significantly lower activity opposite G, an AP site, and $N^{2}$-NaphG than wild-type, whereas both N373S and M407L variants exhibited significantly higher activity opposite those templates. Compared to wild-type REV1, the N497S variant showed significantly increased activity only opposite G and an AP site but not opposite $N^{2}$-NaphG, while the K388N and G498E variants showed significantly increased activity only opposite G.

\section{Steady-State Kinetics of dNTP Incorporation Opposite G, an AP site, and $\boldsymbol{N}^{2}$-NaphG by the Wild-Type and Variant REV1 Enzymes}

To assess the quantitative alterations in both the efficiency and accuracy of 12 REV1 variants for nucleotide incorporation opposite unmodified $\mathrm{G}$ and two DNA lesions, an AP site, and $N^{2}$-NaphG, we performed steady-state kinetic analysis of dNTP incorporation opposite template G, an AP site, or $N^{2}$-NaphG on 24-mer/36-mer primer-templates. Incorporations of dATP opposite $\mathrm{G}$ and the two adducts were not determined due to much less efficient activity than with other dNTPs. We estimated the specificity constant $\left(k_{\mathrm{cat}} / K_{\mathrm{m}}\right)$ and the misinsertion frequency ( $f_{\text {ins }}$ ) (or dNTP selectivity ratio) as semiquantitative indexes that relate to nucleotide insertion efficiency and fidelity of a distributive REV1 enzyme, respectively, as employed previously. ${ }^{20,50}$ Wild-type REV1 incorporated dCTP in large preference (200- to 500-fold) to dTTP and dGTP opposite G and the two lesions, and this 
pattern was also observed with all the variants studied (Tables 2-4). Wild-type REV1 incorporated dCTP opposite an AP site with an efficiency 16-fold less than that opposite G, while incorporating the correct dCTP opposite $N^{2}$-NaphG with an efficiency comparable to that opposite unmodified $\mathrm{G}$ (Tables 2-4), in good agreement with previous reports for fulllength REV1. ${ }^{20,50}$ The misinsertion frequencies (i.e. non-dCTP selectivity ratios) for nucleotide insertion by wild-type REV1 opposite $N^{2}$-NaphG and an AP site were similar or 2- to 3-fold lower than those opposite G. The F427L, R434Q, M656V, D700N, R704Q, and P831L variants showed 2- to 3-fold decreases in $k_{\text {cat }} / K_{\mathrm{m}}$ for dCTP insertion opposite G compared to wild-type REV1. These six variants also showed 2- to 8-fold decreases in $k_{\text {cat }} / K_{\mathrm{m}}$ for dCTP insertion opposite an AP site and $N^{2}$-NaphG compared to wild-type REV1. It is of note that the F427L and M656V variants displayed a relatively high (6- or 8fold) reduction in $k_{\text {cat }} / K_{\mathrm{m}}$ for dCTP insertion, respectively opposite AP site and $N^{2}$-NaphG. These steady-state kinetic results are in good accordance with the patterns of weakened primer extension by the variants in Figure 3. It is also of note that the N373S and M407L variants showed 2- to 3 -fold increases in $k_{\mathrm{cat}} / K_{\mathrm{m}}$ for dCTP insertion opposite G, an AP site, and $N^{2}$-NaphG compared to wild-type REV1 but the N497S variant showed 2-fold increases in $k_{\text {cat }} / K_{\mathrm{m}}$ for dCTP insertion opposite G and an AP site (but not opposite $N^{2}$-NaphG). The $\mathrm{K} 388 \mathrm{~N}, \mathrm{~S} 485 \mathrm{~L}$, and G498E variants showed 2-fold increases in $k_{\text {cat }} / K_{\mathrm{m}}$ for dCTP insertion only opposite $\mathrm{G}$ but not opposite the lesions. Interestingly, some of the variants with altered activity also showed slight alterations in nucleotide insertion selectivity opposite $\mathrm{G}$ and the lesions. The N373S variant showed 2-fold decreases in insertion selectivities of dTTP and dGTP opposite G, an AP site, and $N^{2}$-NaphG, while the R704Q variant showed 2-fold increases in those opposite an AP site and $N^{2}$-NaphG. The M656V variant showed 3- to 4fold decreases in insertion selectivities for dTTP and dGTP opposite G and an AP site. The F427L and R434Q variants showed 3- and 4-fold decreases in dTTP misinsertion frequencies opposite $N^{2}$-NaphG.

\section{Binding of Wild-Type and Variant REV1 Enzymes to DNA Substrates Containing G, an AP site, and $N^{2}$-NaphG}

To evaluate the effects of amino acid changes in twelve REV1 variants on the DNA binding affinity of REV1, we performed fluorescence polarization assays using fluorescein-labeled DNA substrates and REV1 proteins. REV1 proteins were titrated into each of three $5^{\prime}$-FAMlabeled DNA substrates (containing G, AP site, or $N^{2}$-NaphG) and the changes in fluorescence polarization were measured. The equilibrium dissociation constants ( $\left.K_{\mathrm{d}, \mathrm{DNA}}\right)$ were yielded by fitting the fluorescence polarization values as a function of the REV1 concentration to a quadratic equation (Table 5). The wild-type REV1 bound to undamaged DNA with a $K_{\mathrm{d}, \mathrm{DNA}}$ of $39 \mathrm{nM}$, which was similar to that for an AP site- or $N^{2}$-NaphGcontaining DNA, indicating that the DNA binding affinity of REV1 is not affected much by a template AP site or $N^{2}$-NaphG at the primer-template junction. Among six variants with the diminished insertion efficiency opposite template $\mathrm{G}$ and the lesions, four variantsF427L, R434Q, M656V, and R704Q-had 2- to 3-fold higher $K_{\mathrm{d}, \mathrm{DNA}}$ values for all three DNA substrates than did wild-type REV1, indicating slight decreases in DNA-binding affinity of REV1 by those variations. The P831L variant showed a 3-fold increase in $K_{\mathrm{d} \text {,DNA }}$ value only for the AP-site-containing DNA but not for undamaged and $N^{2}$-NaphGcontaining DNA, indicating a selective decrease in the binding affinity of REV1 for AP-site- 
containing DNA by the P831L substitution. The N373S, N497S, and G498E variants displayed very slight (60-80\%) increases in the binding affinity of REV1 for some DNA substrates.

\section{Binding for G4 DNA Substrates and Steady-State Kinetics of dCTP Insertion Opposite the First Tetrad-Guanine on G4 DNA by the Wild-Type REV1 and the N373S Variant}

A recent report on the superior G4 DNA binding affinity of REV1 ${ }^{52}$ prompted us to further evaluate whether twelve selected genetic variations might alter the G4 DNA binding of REV1. Therefore, we determined the equilibrium dissociation constants $\left(K_{\mathrm{d}, \mathrm{DNA}}\right)$ of twelve REV1 variants for G4 DNA using fluorescence polarization assay. Wild-type REV1 bound to the G4 DNA substrate very tightly with a $K_{\mathrm{d}, \mathrm{DNA}}$ of $4.7 \mathrm{nM}$, which was considerably (6to 9-fold) lower than that for non-G4 DNA substrates (Table 5), as reported previously. ${ }^{52}$ Most of the tested REV1 variations did not substantially change the $K_{\mathrm{d}, \mathrm{DNA}}$ of REV1 for G4 DNA, but interestingly the N373S variation caused a 3-fold decrease in the $K_{\mathrm{d}, \mathrm{DNA}}$ of REV1 for G4 DNA, indicating a significant enhancement in G4 DNA binding affinity of REV1 by this variation. We further analyzed the effect of N373S variation on dCTP insertion efficiency opposite the first tetrad G of G4 DNA substrates, in comparison with the wildtype REV1 and other variants, using steady-state kinetic analysis (Table 6). REV1 yielded mainly one-base extended products opposite the first tetrad $\mathrm{G}$ at lower concentrations of dCTP (around or below the $K_{\mathrm{m}}$ ) and also generated some products extended by up to three bases (opposite a run of three Gs on the template) at higher concentrations of dCTP. Only the N373S variant showed a significant increase (2-fold) in catalytic efficiency $\left(k_{\mathrm{cat}} / K_{\mathrm{m}}\right)$ for dCTP incorporation opposite the first tetrad G compared to the wild-type, indicating a slight facilitation of dCTP insertion activity of REV1 opposite the first tetrad G due to this substitution. In contrast, the F427L, R434Q, M656V, D700N, R704Q, and P831L variants (which displayed reduced insertion efficiencies opposite $\mathrm{G}$ and two lesions) showed significant decreases (2- to 4 -fold) in $k_{\text {cat }} / K_{\mathrm{m}}$ for dCTP incorporation opposite the first tetrad G compared to wild-type REV1, indicating a general decrease in polymerase activity in those variants.

\section{DISCUSSION}

In this investigation we report that nine germline missense variations of the human $R E V 1$ gene partially alter the in vitro enzymatic function of REV1 opposite an AP site, a bulky $N^{2}$ $\mathrm{G}$ adduct, and a $\mathrm{G} 4$ motif. We selected 12 reported missense REV1 variants on the bases of their locations, predicted effects, population frequencies, and/or clinical associations and then investigated their enzymatic properties. Our results indicate that the F427L, R434Q, M656V, D700N, R704Q, and P831L variations substantially (up to 8-fold) impair the catalytic activity of REV1 opposite a G, an AP site, an $N^{2}$-NaphG adduct, and a G4 motif, while the N373S, M407L, and N497S variations slightly facilitated the catalytic activity of REV1 opposite a G, an AP site, and/or $N^{2}$-NaphG. Only the N373S variation, reported as an SNP associated with increased cervical cancer risk, resulted in a considerable (3-fold) increase in the G4 DNA-binding affinity of REV1, as well as a 2-fold enhancement in its catalytic activity opposite the first tetrad G of the G4 DNA substrate. To the best of our knowledge, this is the first report identifying catalytically altered germ-line variants of 
human REV1 in detailed biochemical characterization, although most of them-except the $\mathrm{N} 373 \mathrm{~S}-$ seem to be rare in that their MAFs are $\leq 1 \%$ (Table 1 ).

Structural information on human REV1 may be helpful in understanding the biochemical alterations in some genetic variants (Figure 2). The catalytic core of human REV1 possesses the classic DNA polymerase domains (fingers, palm, and thumb), the PAD domain that has a G-loop to interact with an evicted template $\mathrm{G}$, the unique $\mathrm{N}$-digit domain that fills a gap between the PAD and the palm, and the two unique insertions (I1 and I2) that augment the palm and the fingers respectively, as evidenced by the crystal structure of human REV1DNA-dCTP ternary complex. ${ }^{19}$ It is notable that the N373S substitution, located in the Ndigit domain, led to enhancements in the DNA binding and catalytic ability of REV1 at G4 DNA. This observed effect is hard to explain but it is conceivable that the substituted residue (Ser), which is smaller in size than the wild-type residue (Asn), in the long aB helix of the $\mathrm{N}$-digit domain might allow REV1 to better accommodate the G-quadruplex conformation. The moderate decreases in catalytic efficiency in the F427L, R434Q, M656V, and R704Q variants seem to be at least partially related to their reduced DNA binding affinities. The R704Q and R434Q variants, located in the linker region or the fingers domain respectively, lose a positively charged Arg residue facing or remote from the sugar-phosphate DNA backbone, which might affect the interaction of REV1 with DNA directly or indirectly. The M656V variant, located in the thumb domain, loses a sulfur-containing residue (Met) close to the phosphodiester DNA backbone, which might cause local structural changes to interfere with its DNA binding. The F427L variation, located in the fingers domain, causes the loss of a conserved aromatic residue (Phe) near the incoming dCTP at the primertemplate junction, which might perturb the local conformation in the active site of REV1 and thus adversely affect the catalysis and DNA binding of REV1. It is not clear how the D700N variation could impair the catalytic activity of REV1, but it might be related to the loss of a conserved negatively charged residue (Asp), which might destabilize the local structure in the linker region to connect the thumb and PAD domains. It is also notable that M407L, N497S, and P831L variations located in the unstructured or loop regions at the outside of REV1, could change the catalytic activity, which might disturb local dynamic conformations in disordered regions of REV1.

The 12 germline REV1 variants characterized in this study can be categorized into three types according to the changes in their catalytic properties opposite four DNA templatesG, AP site, $N^{2}$-NaphG, and G4 motif-when compared to wild-type (Tables 2-6 and Figure 5). The first type is the "wild-type-like" variants (K388N, S485L, and G498E), which have slightly enhanced catalytic activity at $\mathrm{G}$ but retain similar catalytic activity at the other three templates. The second type is the hypoactive variants (F427L, R434Q, M656V, D700N, R704Q, and P831L), which have diminished catalytic activity opposite all four templates. The third type is the hyperactive variants (N373S, M407L, and N497S), which have enhanced catalytic activity opposite at least two templates and which can be further subcategorized into three subtypes according to their substrate specificities. One is the N373S variant, which is broadly overactive at all four templates - normal G, two lesions (AP-site and $N^{2}$-NaphG), and a non-B-form G4 DNA - and has a distinctly higher G4 DNA binding affinity. Another is the M407L variant, which is overactive at a normal $\mathrm{G}$ and two lesions but not a G4 motif. The other is the N497S variant, which is overactive only at a 
normal G and an AP site but not opposite an $N^{2}$-NaphG and a G4 motif. Among seven variants predicted to be damaging by SIFT and/or Polyphen, three variants were found to be not hypoactive. Among the five variants predicted to be tolerated or non-damaging, two variants were found to be hypoactive, indicating the relatively high false-negative and positive errors ( $40 \%$ each) of these in silico predictions, which are slightly higher than the previously estimated errors. It was reported that the false-negative and false-positive errors are $31 \%$ and $20 \%$ for SIFT and $31 \%$ and $9 \%$ for PolyPhen. ${ }^{49}$ It is also noticeable that among three hyperactive variants, two variants were predicted to be non-damaging but one variant was predicted to be damaging. Therefore, it may be considered necessary to validate the in silico predicted effects of missense genetic variants using biochemical or other functional assays, regardless of the predictions. Our results suggest the need and importance of biochemical approaches to characterize functional variants among numerous uninvestigated genetic variants and to further distinguish between underactive and overactive variants in detail.

It might be difficult to predict how the catalytically altered human REV1 variants would modify cellular or organismal phenotypes, because there are only limited in vivo experimental data on the catalytic role of REV1 yet. Previous studies with the catalytically inactive REV1 mutant models have suggested that REV1 catalytic activity may be required for replicative bypass of AP sites, $N^{2}$-G adducts, and $1, N^{6}$-etheno-A in yeast cells, ${ }^{24,25,53}$ for hypermutation of the immunoglobulin gene in avian cells and mice, ${ }^{26,27}$ and for G4 DNA replication on the leading strand in avian cells. ${ }^{29}$ In this regard, it might be conceivable that hypoactive or hyperactive variants of REV1 diminish or enhance REV1 dCTP insertion capacity opposite the aforementioned cognate DNA substrates and thus result in a corresponding decrease or increase of REV1 C-inserted products, which might accordingly change the mutation outcomes (i.e. rate and spectrum) of cognate DNA lesions and/or the maintenance level of genomic G4 DNA sequences in individuals carrying those genetic variations. It is also likely that some variations in the other REV1 domains (e.g., BRCT, UBM, PID) might be able to alter the noncatalytic scaffolding function of REV1 and thus influence TLS, repair, and mutagenesis events upon DNA damage in cells, although this aspect was not investigated this study.

In conclusion, our results suggest that nine missense germline genetic variations in human REV1 gene can either diminish or enhance the catalytic activity of REV1 opposite an AP site, $N^{2}$-guanyl lesion and/or G4 DNA, which may possibly result in varied mutation phenotypes and susceptibilities to certain chemical and viral carcinogens in the affected individuals. It can also be speculated that the N373S SNP might enhance the replicative bypass capacity of REV1 opposite AP and G4 sites, which could be derived from HPV infection. Although our results may provide some insight into the altered lesion and G4 bypass capacity, it is still not clear how the N373S SNP leads to a high risk of cervical cancer. There also exists a possibility that the N373S SNP might interact with some other linked functional SNPs that could somehow influence the reported cancer association in other ways. Our identification of catalytically altered germline variants of REV1 may provide insight into our understanding of individual differences in disease risk such as cancer. The exact contributions of the functional germline variants of REV1 to individual 
disease risks remain unclear and needs to be further elucidated in future studies because they may provide novel preventive and therapeutic measures.

\section{Supplementary Material}

Refer to Web version on PubMed Central for supplementary material.

\section{Acknowledgments}

Funding

This work was supported by the Basic Science Research Program through the National Research Foundation of Korea funded by the Ministry of Education (Grant NRF-2012R1A1A2042391) (to J.-Y.C.), Samsung Biomedical Research Institute grant, \#SBRI SMX1150771 (to J.-Y.C.), the National Institutes of Health Grants R01 CA183895 (to R.L.E.) and R01 ES010375 and R01 ES010546 (to F.P.G.).

ABBREVIATIONS

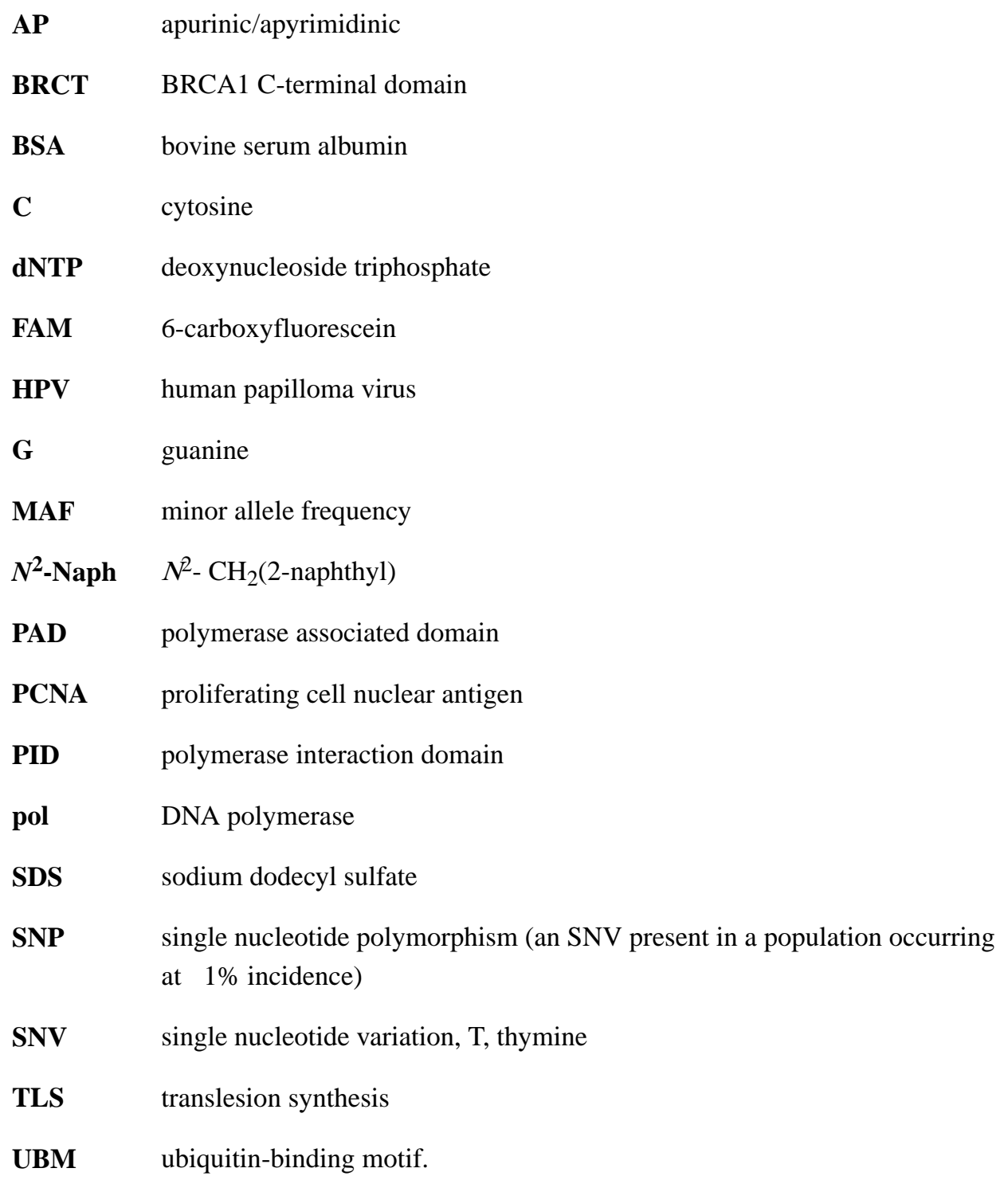




\section{REFERENCES}

1. Friedberg, EC.; Walker, GC.; Siede, W.; Wood, RD.; Schultz, RA.; Ellenberger, T. DNA Repair And Mutagenesis. 2nd. Washington, D. C: American Society for Microbiology Press; 2006.

2. Hoeijmakers JH. DNA damage, aging, and cancer. N. Engl. J. Med. 2009; 361:1475-1485. [PubMed: 19812404]

3. Guengerich FP. Interactions of carcinogen-bound DNA with individual DNA polymerases. Chem. Rev. 2006; 106:420-452. [PubMed: 16464013]

4. Choi J-Y, Guengerich FP. Analysis of the effect of bulk at $N^{2}$-alkylguanine DNA adducts on catalytic efficiency and fidelity of the processive DNA polymerases bacteriophage T7 exonuclease ${ }^{-}$ and HIV-1 reverse transcriptase. J. Biol. Chem. 2004; 279:19217-19229. [PubMed: 14985330]

5. Einolf HJ, Guengerich FP. Fidelity of nucleotide insertion at 8-oxo-7,8-dihydroguanine by mammalian DNA polymerase $\delta$. Steady-state and pre-steady-state kinetic analysis. J. Biol. Chem. 2001; 276:3764-3771. [PubMed: 11110788]

6. Sabouri N, Viberg J, Goyal DK, Johansson E, Chabes A. Evidence for lesion bypass by yeast replicative DNA polymerases during DNA damage. Nucleic Acids Res. 2008; 36:5660-5667. [PubMed: 18772226]

7. Schmitt MW, Matsumoto Y, Loeb LA. High fidelity and lesion bypass capability of human DNA polymerase $\delta$. Biochimie. 2009; 91:1163-1172. [PubMed: 19540301]

8. Choi J-Y, Guengerich FP. Adduct size limits efficient and error-free bypass across bulky $N^{2}$-guanine DNA lesions by human DNA polymerase $\eta$. J. Mol. Biol. 2005; 352:72-90. [PubMed: 16061253]

9. Friedberg EC. Suffering in silence: the tolerance of DNA damage. Nat. Rev. Mol. Cell. Biol. 2005; 6:943-953. [PubMed: 16341080]

10. Sale JE. Translesion DNA synthesis and mutagenesis in eukaryotes. Cold Spring Harb. Perspect. Biol. 2013; 5:a012708. [PubMed: 23457261]

11. Choi, J-Y.; Eoff, RE.; Guengerich, FP. Bypass DNA polymerases. In: Penning, TM., editor. Chemical Carcinogenesis. New York, NY: Humana Press; 2011. p. 345-373.

12. Prakash S, Johnson RE, Prakash L. Eukaryotic translesion synthesis DNA polymerases: specificity of structure and function. Annu. Rev. Biochem. 2005; 74:317-353. [PubMed: 15952890]

13. Waters LS, Minesinger BK, Wiltrout ME, D'Souza S, Woodruff RV, Walker GC. Eukaryotic translesion polymerases and their roles and regulation in DNA damage tolerance. Microbiol. Mol. Biol. Rev. 2009; 73:134-154. [PubMed: 19258535]

14. Guo C, Fischhaber PL, Luk-Paszyc MJ, Masuda Y, Zhou J, Kamiya K, Kisker C, Friedberg EC. Mouse Rev1 protein interacts with multiple DNA polymerases involved in translesion DNA synthesis. EMBO J. 2003; 22:6621-6630. [PubMed: 14657033]

15. Murakumo Y, Ogura Y, Ishii H, Numata S, Ichihara M, Croce CM, Fishel R, Takahashi M. Interactions in the error-prone postreplication repair proteins hREV1, hREV3, and hREV7. J. Biol. Chem. 2001; 276:35644-35651. [PubMed: 11485998]

16. Ohashi E, Murakumo Y, Kanjo N, Akagi J, Masutani C, Hanaoka F, Ohmori H. Interaction of hREV1 with three human Y-family DNA polymerases. Genes Cells. 2004; 9:523-531. [PubMed: 15189446]

17. Tissier A, Kannouche P, Reck MP, Lehmann AR, Fuchs RP, Cordonnier A. Co-localization in replication foci and interaction of human Y-family members, DNA polymerase pol $\eta$ and REVl protein. DNA Repair. 2004; 3:1503-1514. [PubMed: 15380106]

18. Nair DT, Johnson RE, Prakash L, Prakash S, Aggarwal AK. Rev1 employs a novel mechanism of DNA synthesis using a protein template. Science. 2005; 309:2219-2222. [PubMed: 16195463]

19. Swan MK, Johnson RE, Prakash L, Prakash S, Aggarwal AK. Structure of the human Rev1-DNAdNTP ternary complex. J. Mol. Biol. 2009; 390:699-709. [PubMed: 19464298]

20. Choi J-Y, Guengerich FP. Kinetic analysis of translesion synthesis opposite bulky $N^{2}$ - and $O^{6}$ alkylguanine DNA adducts by human DNA polymerase REV1. J. Biol. Chem. 2008; 283:2364523655. [PubMed: 18591245]

21. Nelson JR, Lawrence CW, Hinkle DC. Deoxycytidyl transferase activity of yeast REV1 protein. Nature. 1996; 382:729-731. [PubMed: 8751446] 
22. Washington MT, Minko IG, Johnson RE, Haracska L, Harris TM, Lloyd RS, Prakash S, Prakash L. Efficient and error-free replication past a minor-groove N2-guanine adduct by the sequential action of yeast Rev1 and DNA polymerase $\zeta$. Mol. Cell. Biol. 2004; 24:6900-6906. [PubMed: 15282292]

23. Zhang Y, Wu X, Rechkoblit O, Geacintov NE, Taylor JS, Wang Z. Response of human REV1 to different DNA damage: preferential dCMP insertion opposite the lesion. Nucleic Acids Res. 2002; 30:1630-1638. [PubMed: 11917024]

24. Kim N, Mudrak SV, Jinks-Robertson S. The dCMP transferase activity of yeast Rev1 is biologically relevant during the bypass of endogenously generated AP sites. DNA Repair. 2011; 10:1262-1271. [PubMed: 22024240]

25. Wiltrout ME, Walker GC. The DNA polymerase activity of Saccharomyces cerevisiae Rev1 is biologically significant. Genetics. 2011; 187:21-35. [PubMed: 20980236]

26. Masuda K, Ouchida R, Li Y, Gao X, Mori H, Wang JY. A critical role for REV1 in regulating the induction of C:G transitions and A:T mutations during Ig gene hypermutation. J. Immunol. 2009; 183:1846-1850. [PubMed: 19587019]

27. Ross AL, Sale JE. The catalytic activity of REV1 is employed during immunoglobulin gene diversification in DT40. Mol. Immunol. 2006; 43:1587-1594. [PubMed: 16263170]

28. Northam MR, Moore EA, Mertz TM, Binz SK, Stith CM, Stepchenkova EI, Wendt KL, Burgers PM, Shcherbakova PV. DNA polymerases $\zeta$ and Rev1 mediate error-prone bypass of non-B DNA structures. Nucleic Acids Res. 2014; 42:290-306. [PubMed: 24049079]

29. Sarkies P, Reams C, Simpson LJ, Sale JE. Epigenetic instability due to defective replication of structured DNA. Mol. Cell. 2010; 40:703-713. [PubMed: 21145480]

30. Hlavin EM, Smeaton MB, Noronha AM, Wilds CJ, Miller PS. Cross-link structure affects replication-independent DNA interstrand cross-link repair in mammalian cells. Biochemistry. 2010; 49:3977-3988. [PubMed: 20373772]

31. Sharma S, Hicks JK, Chute CL, Brennan JR, Ahn JY, Glover TW, Canman CE. REV1 and polymerase $\zeta$ facilitate homologous recombination repair. Nucleic Acids Res. 2012; 40:682-691. [PubMed: 21926160]

32. Shen X, Jun S, O'Neal LE, Sonoda E, Bemark M, Sale JE, Li L. REV3 and REV1 play major roles in recombination-independent repair of DNA interstrand cross-links mediated by monoubiquitinated proliferating cell nuclear antigen (PCNA). J. Biol. Chem. 2006; 281:1386913872. [PubMed: 16571727]

33. He X, Ye F, Zhang J, Cheng Q, Shen J, Chen H. REV1 genetic variants associated with the risk of cervical carcinoma. Eur. J. Epidemiol. 2008; 23:403-409. [PubMed: 18470628]

34. Sakiyama T, Kohno T, Mimaki S, Ohta T, Yanagitani N, Sobue T, Kunitoh H, Saito R, Shimizu K, Hirama C, Kimura J, Maeno G, Hirose H, Eguchi T, Saito D, Ohki M, Yokota J. Association of amino acid substitution polymorphisms in DNA repair genes TP53, POLI, REV1 and LIG4 with lung cancer risk. Int. J. Cancer. 2005; 114:730-737. [PubMed: 15609317]

35. Alexandrov LB, Nik-Zainal S, Wedge DC, Aparicio SA, Behjati S, Biankin AV, Bignell GR, Bolli N, Borg A, Borresen-Dale AL, Boyault S, Burkhardt B, Butler AP, Caldas C, Davies HR, Desmedt C, Eils R, Eyfjord JE, Foekens JA, Greaves M, Hosoda F, Hutter B, Ilicic T, Imbeaud S, Imielinski M, Jager N, Jones DT, Jones D, Knappskog S, Kool M, Lakhani SR, Lopez-Otin C, Martin S, Munshi NC, Nakamura H, Northcott PA, Pajic M, Papaemmanuil E, Paradiso A, Pearson JV, Puente XS, Raine K, Ramakrishna M, Richardson AL, Richter J, Rosenstiel P, Schlesner M, Schumacher TN, Span PN, Teague JW, Totoki Y, Tutt AN, Valdes-Mas R, van Buuren MM, van 't Veer L, Vincent-Salomon A, Waddell N, Yates LR, Australian Pancreatic Cancer Genome, I., Consortium, I. B. C., Consortium, I. M.-S., PedBrain, I. Zucman-Rossi J, Futreal PA, McDermott U, Lichter P, Meyerson M, Grimmond SM, Siebert R, Campo E, Shibata T, Pfister SM, Campbell PJ, Stratton MR. Signatures of mutational processes in human cancer. Nature. 2013; 500:415-421. [PubMed: 23945592]

36. Vieira VC, Leonard B, White EA, Starrett GJ, Temiz NA, Lorenz LD, Lee D, Soares MA, Lambert PF, Howley PM, Harris RS. Human papillomavirus E6 triggers upregulation of the antiviral and cancer genomic DNA deaminase APOBEC3B. MBio. 2014; 5 pii: e2234-14.

37. Burns MB, Temiz NA, Harris RS. Evidence for APOBEC3B mutagenesis in multiple human cancers. Nat. Genet. 2013; 45:977-983. [PubMed: 23852168] 
38. Helleday T, Eshtad S, Nik-Zainal S. Mechanisms underlying mutational signatures in human cancers. Nat. Rev. Genet. 2014; 15:585-598. [PubMed: 24981601]

39. Tluckova K, Marusic M, Tothova P, Bauer L, Sket P, Plavec J, Viglasky V. Human papillomavirus G-quadruplexes. Biochemistry. 2013; 52:7207-7216. [PubMed: 24044463]

40. Bruni L, Diaz M, Castellsague X, Ferrer E, Bosch FX, de Sanjose S. Cervical human papillomavirus prevalence in 5 continents: meta-analysis of 1 million women with normal cytological findings. J. Infect. Dis. 2010; 202:1789-1799. [PubMed: 21067372]

41. Liu G, Markowitz LE, Hariri S, Panicker G, Unger ER. Seroprevalence of 9 human papillomavirus types in the United States, 2005-2006. J. Infect. Dis. 2016; 213:191-198. [PubMed: 26320259]

42. Goricar K, Kovac V, Dolzan V. Polymorphisms in translesion polymerase genes influence treatment outcome in malignant mesothelioma. Pharmacogenomics. 2014; 15:941-950. [PubMed: 24956248]

43. Goricar K, Kovac V, Jazbec J, Zakotnik B, Lamovec J, Dolzan V. Translesion polymerase genes polymorphisms and haplotypes influence survival of osteosarcoma patients. OMICS. 2015; 19:180-185. [PubMed: 25748439]

44. Adzhubei IA, Schmidt S, Peshkin L, Ramensky VE, Gerasimova A, Bork P, Kondrashov AS, Sunyaev SR. A method and server for predicting damaging missense mutations. Nat. Methods. 2010; 7:248-249. [PubMed: 20354512]

45. Ng PC, Henikoff S. Predicting deleterious amino acid substitutions. Genome Res. 2001; 11:863874. [PubMed: 11337480]

46. Ramensky V, Bork P, Sunyaev S. Human non-synonymous SNPs: server and survey. Nucleic Acids Res. 2002; 30:3894-3900. [PubMed: 12202775]

47. Kim J, Song I, Jo A, Shin J-H, Cho H, Eoff RL, Guengerich FP, Choi J-Y. Biochemical analysis of six genetic variants of error-prone human DNA polymerase $\imath$ involved in translesion DNA synthesis. Chem. Res. Toxicol. 2014; 27:1837-1852. [PubMed: 25162224]

48. Song I, Kim E-J, Kim I-H, Park E-M, Lee KE, Shin J-H, Guengerich FP, Choi J-Y. Biochemical characterization of eight genetic variants of human DNA polymerase $\kappa$ involved in error-free bypass across bulky $N^{2}$-guanyl DNA adducts. Chem. Res. Toxicol. 2014; 27:919-930. [PubMed: 24725253]

49. Ng PC, Henikoff S. Predicting the effects of amino acid substitutions on protein function. Ann. Rev. Genomics Hum. Genet. 2006; 7:61-80. [PubMed: 16824020]

50. Choi J-Y, Lim S, Kim E-J, Jo A, Guengerich FP. Translesion synthesis across abasic lesions by human B-family and Y-family DNA polymerases $a, \delta, \eta, \mathbf{~}$,, and REV1. J. Mol. Biol. 2010; 404:34-44. [PubMed: 20888339]

51. Lin W, Xin H, Zhang Y, Wu X, Yuan F, Wang Z. The human REV1 gene codes for a DNA template-dependent dCMP transferase. Nucleic Acids Res. 1999; 27:4468-4475. [PubMed: 10536157]

52. Eddy S, Ketkar A, Zafar MK, Maddukuri L, Choi J-Y, Eoff RL. Human Rev1 polymerase disrupts G-quadruplex DNA. Nucleic Acids Res. 2014; 42:3272-3285. [PubMed: 24366879]

53. Zhou Y, Wang J, Zhang Y, Wang Z. The catalytic function of the Rev1 dCMP transferase is required in a lesion-specific manner for translesion synthesis and base damage-induced mutagenesis. Nucleic Acids Res. 2010; 38:5036-5046. [PubMed: 20388628]

54. Seenisamy J, Rezler EM, Powell TJ, Tye D, Gokhale V, Joshi CS, Siddiqui-Jain A, Hurley LH. The dynamic character of the G-quadruplex element in the c-MYC promoter and modification by TMPyP4. J. Am. Chem. Soc. 2004; 126:8702-8709. [PubMed: 15250722]

55. Ren J, Wen L, Gao X, Jin C, Xue Y, Yao X. DOG 1.0: illustrator of protein domain structures. Cell Res. 2009; 19:271-273. [PubMed: 19153597] 


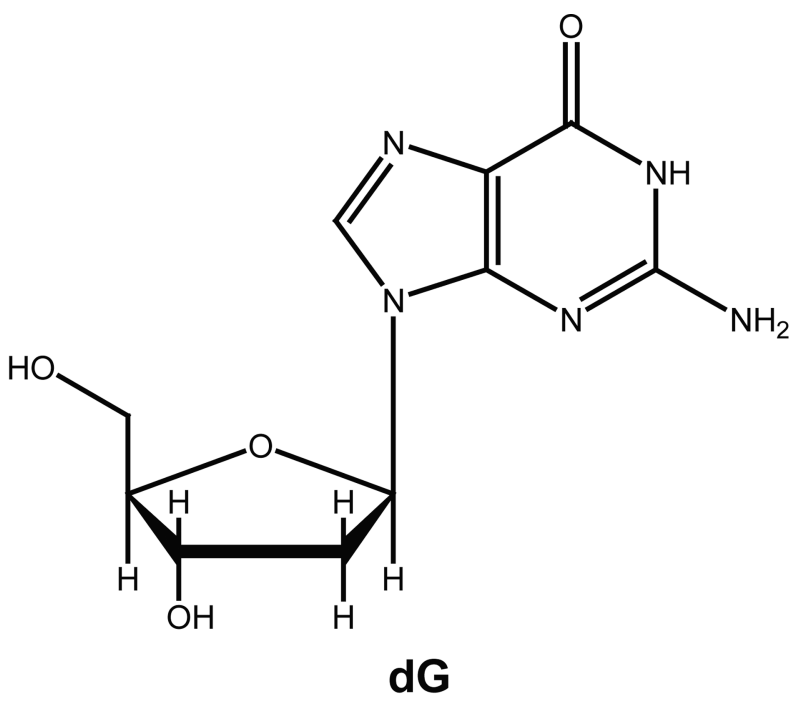

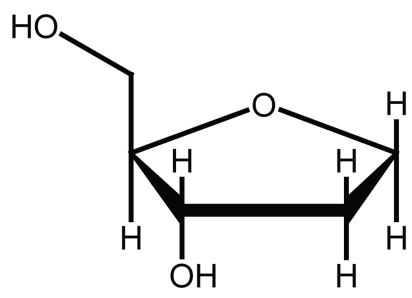

tetrahydrofuran AP site analogue
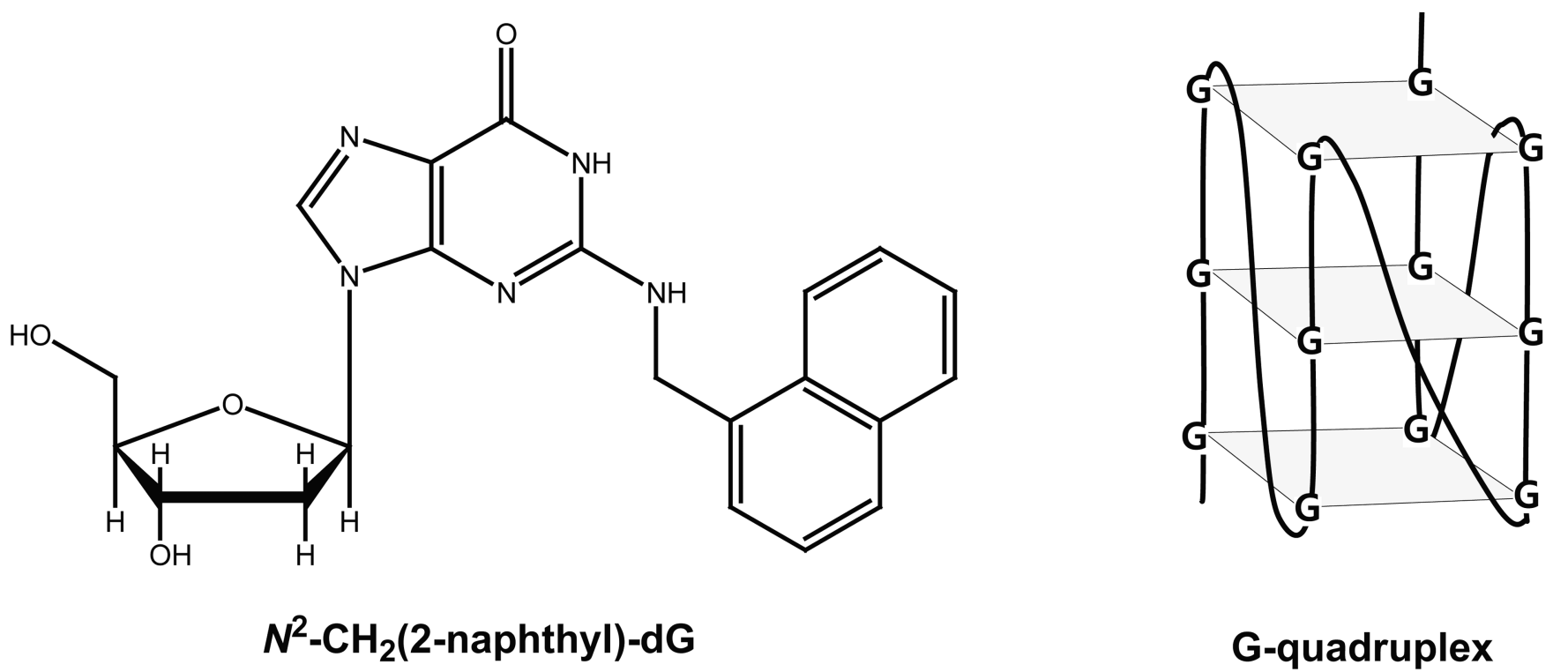

Figure 1. DNA adducts and a G-quadruplex used in this work

Structures of $N^{2}-\mathrm{CH}_{2}$ (2-naphthyl)-dG ( $\left.N^{2}-\mathrm{Naph}-\mathrm{dG}\right)$, tetrahydrofuran (an AP site analog), normal dG, and a schematic structure of a parallel G-quadruplex ${ }^{54}$ are shown. 

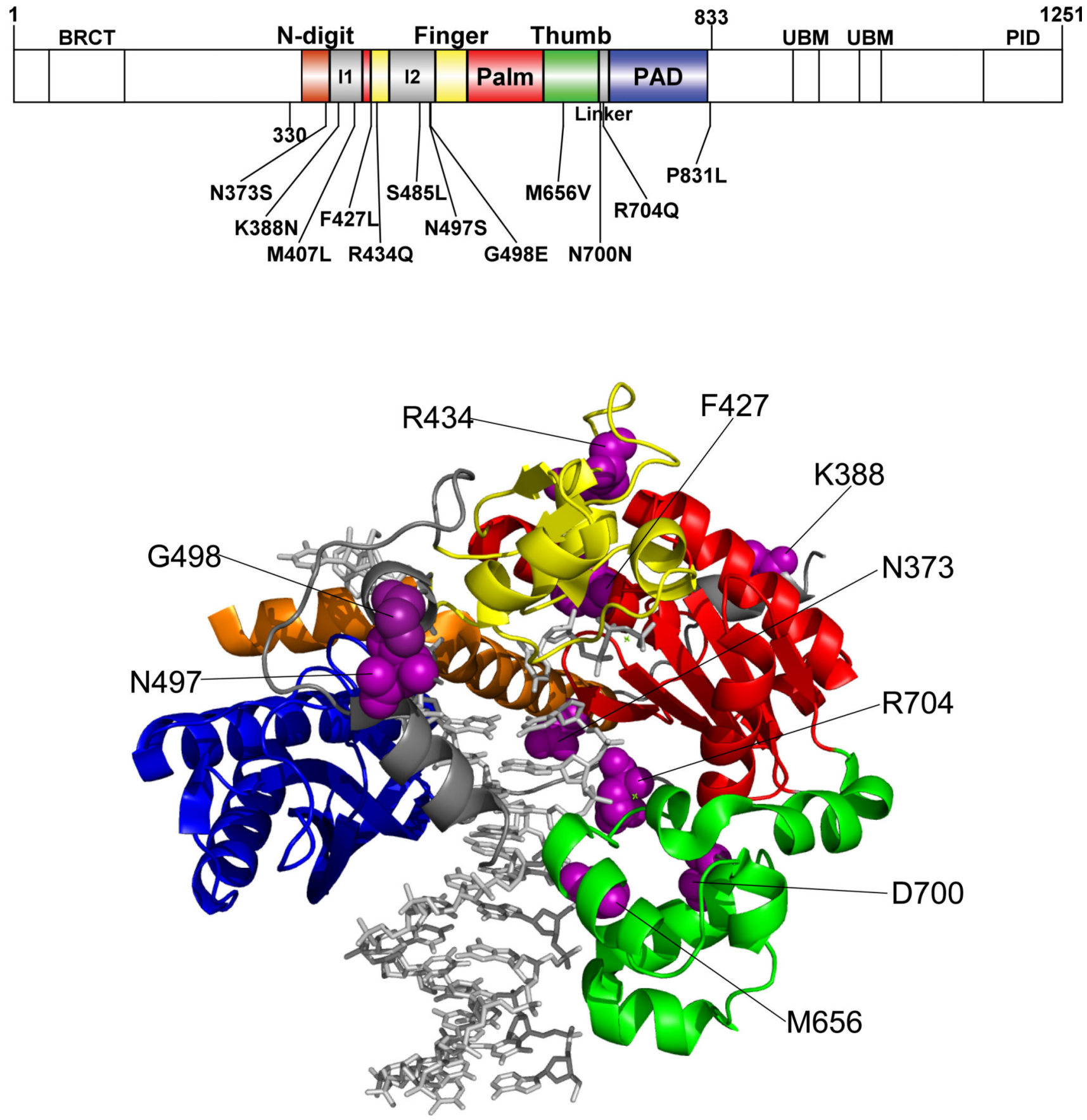

Figure 2. Locations of REV1 genetic variations studied

Structure of human REV1(330-833) (PDB code, 3GQC) bound to primer/template DNA and incoming dCTP is shown using Pymol. REV1(330-833) is shown in cartoon ribbons, and the primer/template DNA and dCTP are shown in gray sticks. The finger, palm, thumb, and PAD domains are colored yellow, red, green, and blue, respectively. Nine amino acid residues (shown in purple spheres) altered in nine genetic REV1 variants are indicated. Three amino acid residues altered in the M407L, N497S, and P831L variants are not illustrated in the model, in that they are not resolved in the crystal structure. The structural 
domains of REV1 are shown in the upper schematic diagram using DOG (version 2.0), ${ }_{5} 5$ where positions of amino acids related to twelve studied variations are indicated. 


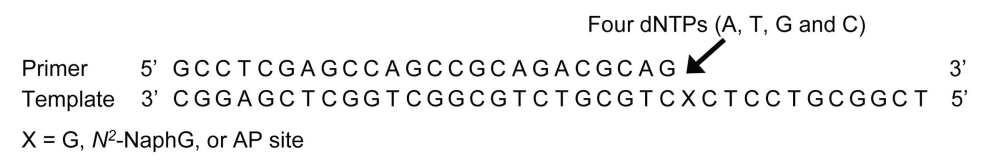

(a)

$X=G$

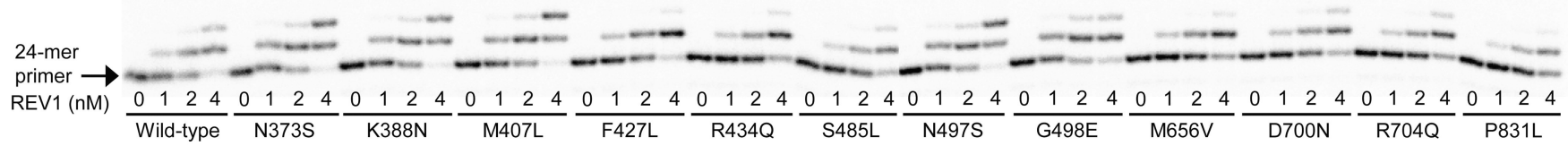

(b)

$\mathrm{X}=\mathrm{AP}$ site

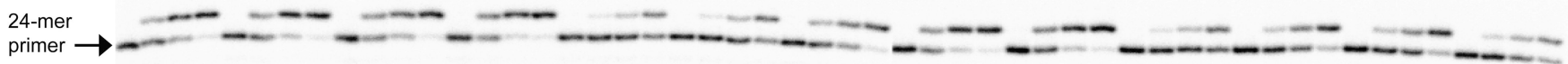

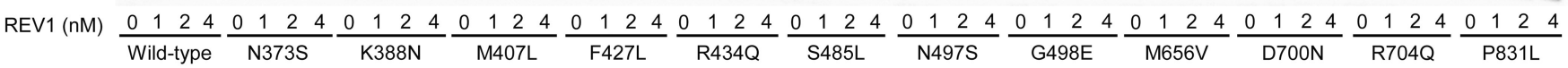

(c) $\mathrm{X}=\mathrm{N}^{2}$-NaphG

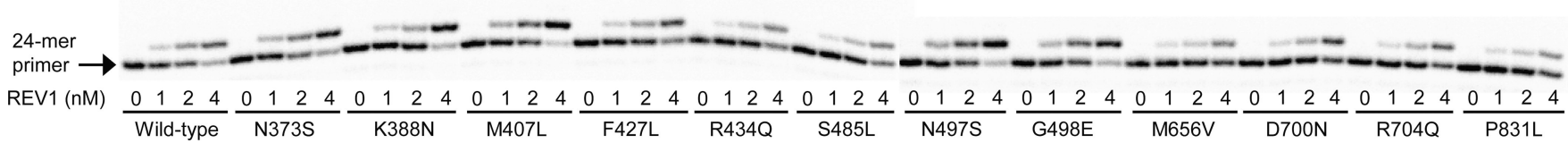

Figure 3. Primer extension opposite G, AP site, and $N^{2}$-NaphG by human wild-type and variant REV1(330-833) enzymes

The ${ }^{32}$ P-labeled primer (24-mer) was annealed with each of three different 36-mer templates containing an unmodified G, AP site, or $N^{2}$-NaphG placed at the 25 th position from the $3^{\prime}$ end. Reactions were done in the presence of all four dNTPs $(50 \mu \mathrm{M}$ each), DNA substrate (100 $\mathrm{nM}$ primer/template), and $\mathrm{MgCl}_{2}(5 \mathrm{mM})$ for $15 \mathrm{~min}$ with increasing concentrations of REV1 (0 - 4 nM) as indicated. (a) Extension opposite G. (b) Extension opposite AP site. (c) Extension opposite $N^{2}-N a p h G$. 


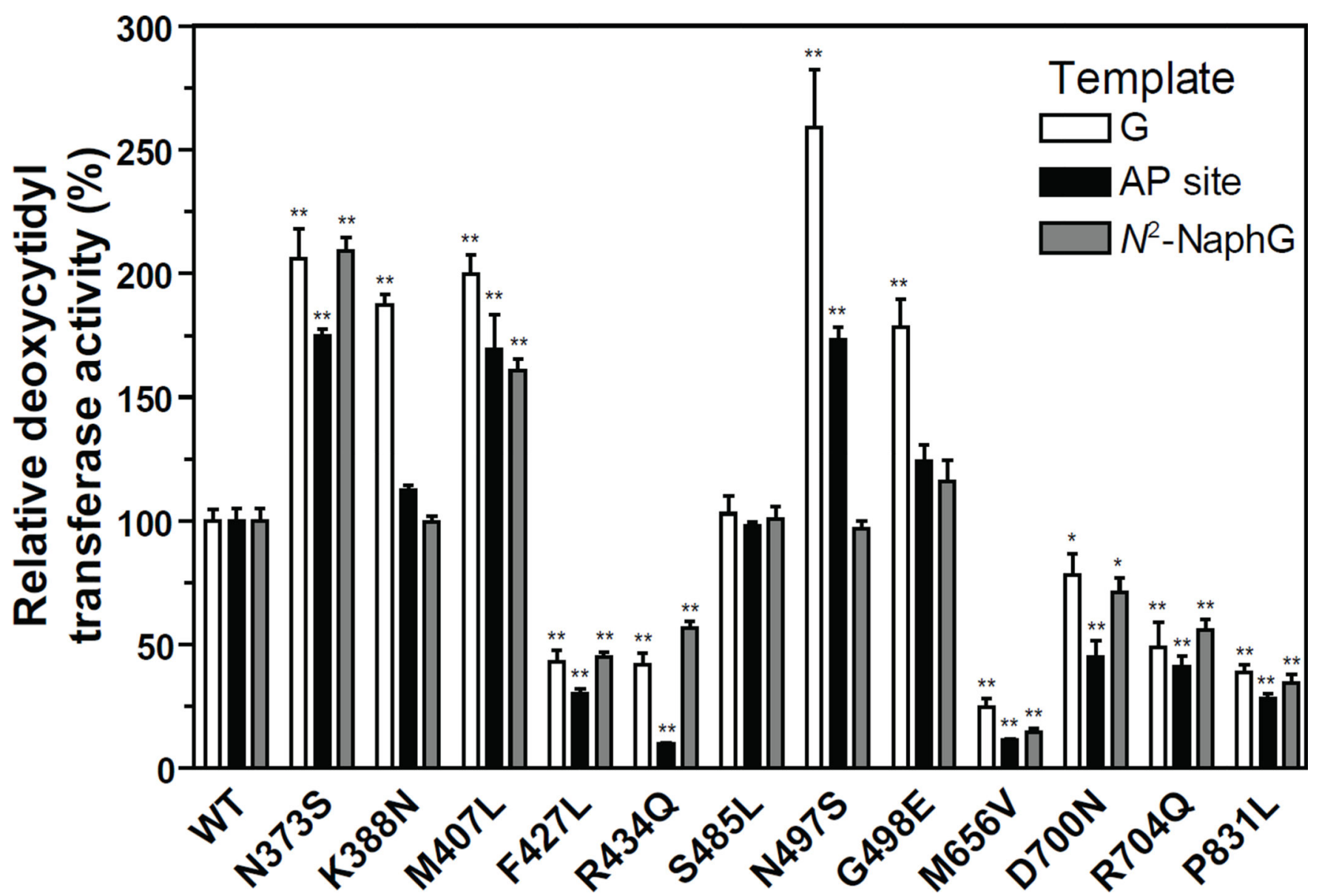

Figure 4. Deoxycytidyl transferase activities of human wild-type and variant REV1(330-833) enzymes opposite G, AP site, and $N^{\mathbf{2}}$-NaphG Deoxycytidyl transferase activities that incorporate dCTP opposite G, AP site, and $N^{2}$ NaphG were determined for wild-type REV1 and variants in the presence of a low concentration of dCTP $\left(1,5\right.$, or $0.5 \mu \mathrm{M}$, respectively for template $\mathrm{G}$, AP site, or $N^{2}$-NaphG), DNA substrate (100 $\mathrm{nM}$ primer/template), and $\mathrm{MgCl}_{2}(5 \mathrm{mM})$ for $10 \mathrm{~min}$ with REV1 (0.5, 0.8 , or $1 \mathrm{nM}$, respectively for template G, AP site, or $\left.N^{2}-\mathrm{NaphG}\right)$. Deoxycytidyl transferase activity was calculated by analyzing the extension product by denaturing gel electrophoresis and phosphorimaging. The mean relative activity of REV1 variants compared with the wildtype enzyme (set to $100 \%$ ) and standard deviation from triplicate assays are shown in the bar graph. ${ }^{*} P<0.05,{ }^{* *} P<0.01$ (two-tailed Student's $t$-test for comparison with the wild-type REV1) 


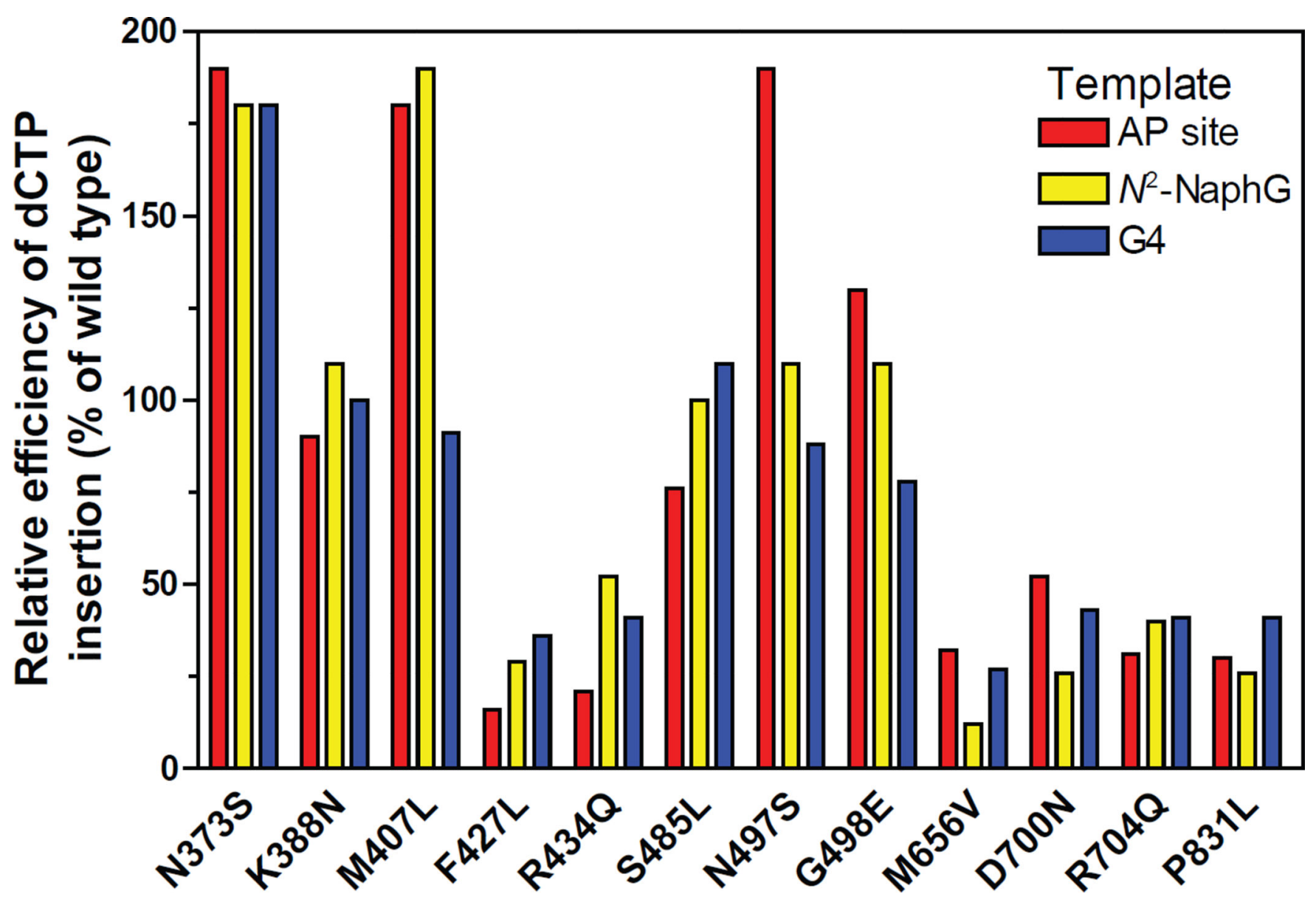

Figure 5. Bypass efficiencies of human REV1(330-833) variants opposite AP site, $N^{2}$-NaphG, and the first tetrad $\mathbf{G}$ compared to that of the wild-type

The bar graph shows the bypass efficiencies of the variant REV1(330-833) enzymes

(relative to that of wild type) for dCTP insertion opposite AP site, and $N^{2}$-NaphG, and G4 DNA based on the kinetic parameters in Tables 2, 3, 4, and 6. 


\section{을 \\ 골}

I

ग

$\frac{-}{\frac{0}{0}}$

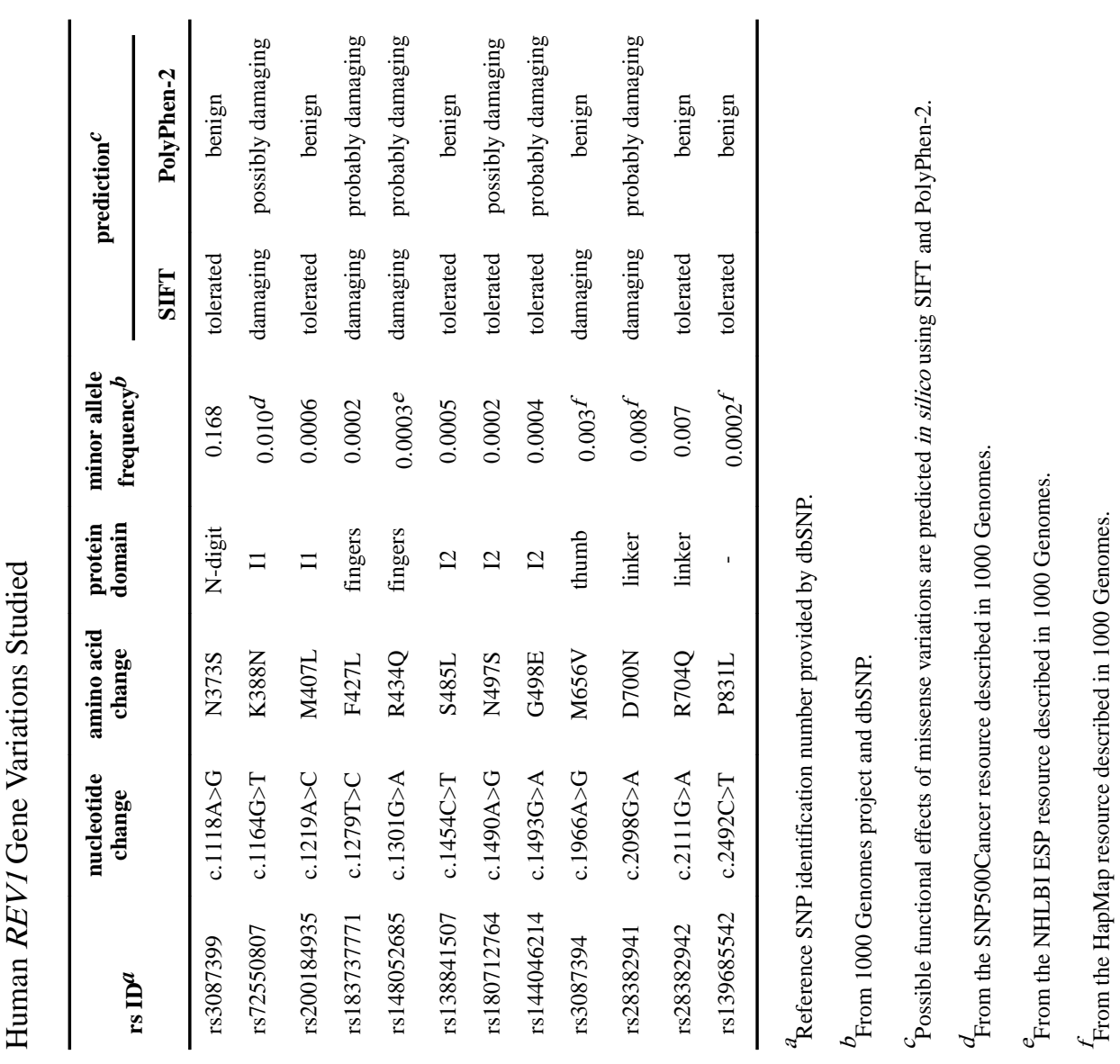

Chem Res Toxicol. Author manuscript; available in PMC 2017 March 21. 


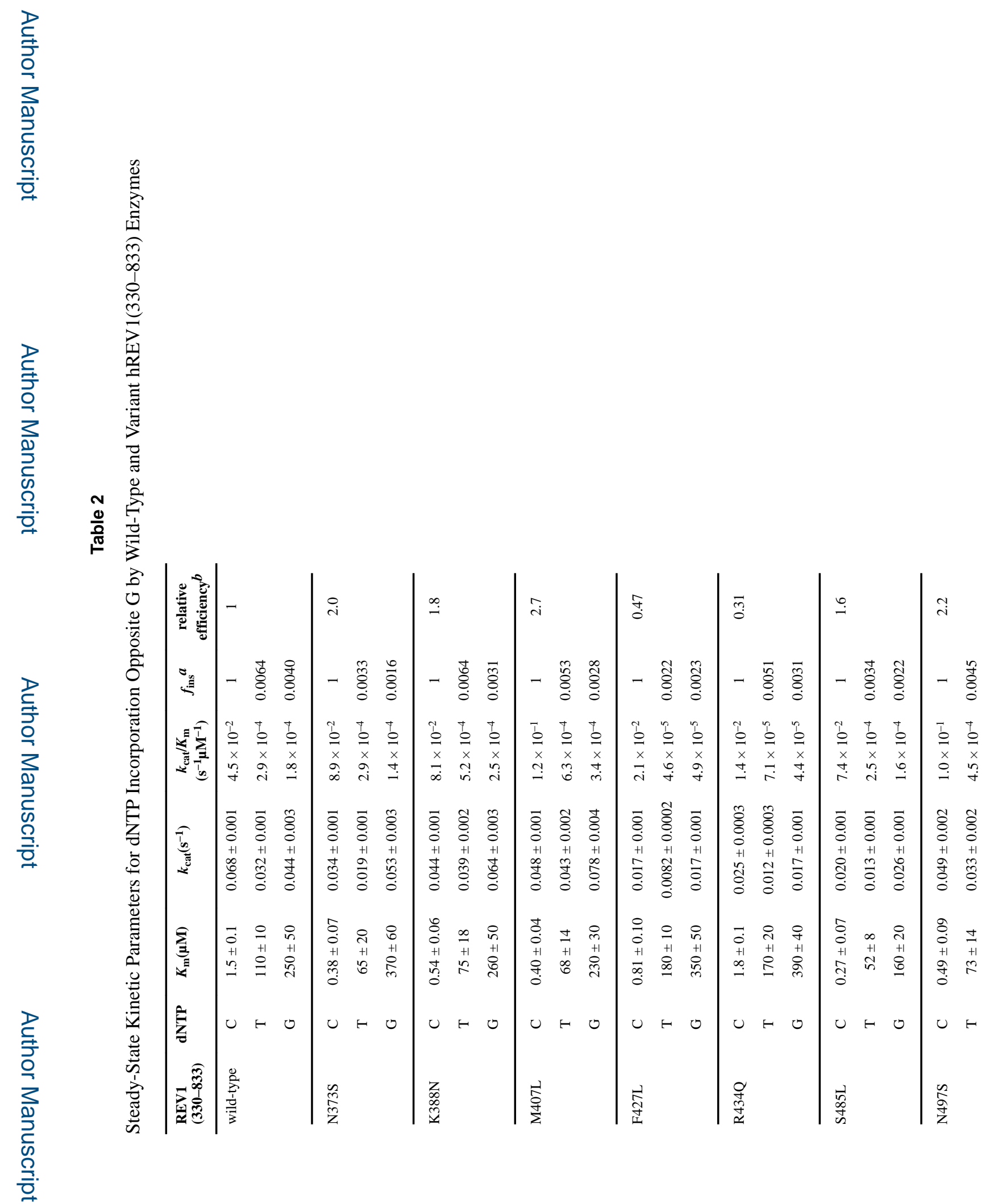

Chem Res Toxicol. Author manuscript; available in PMC 2017 March 21. 


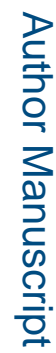

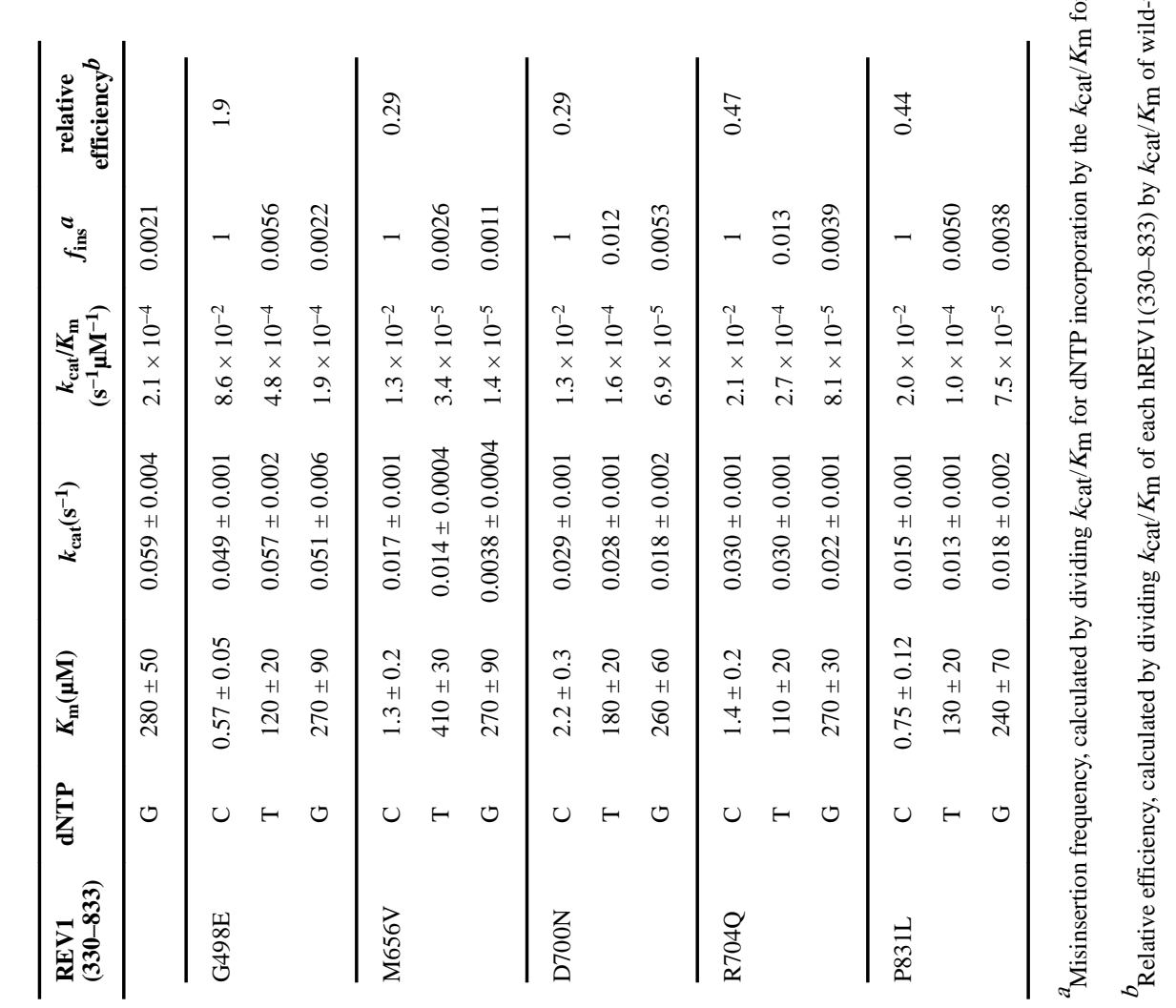

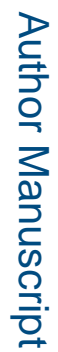

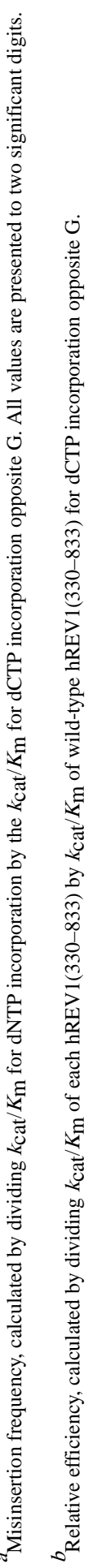

Chem Res Toxicol. Author manuscript; available in PMC 2017 March 21. 


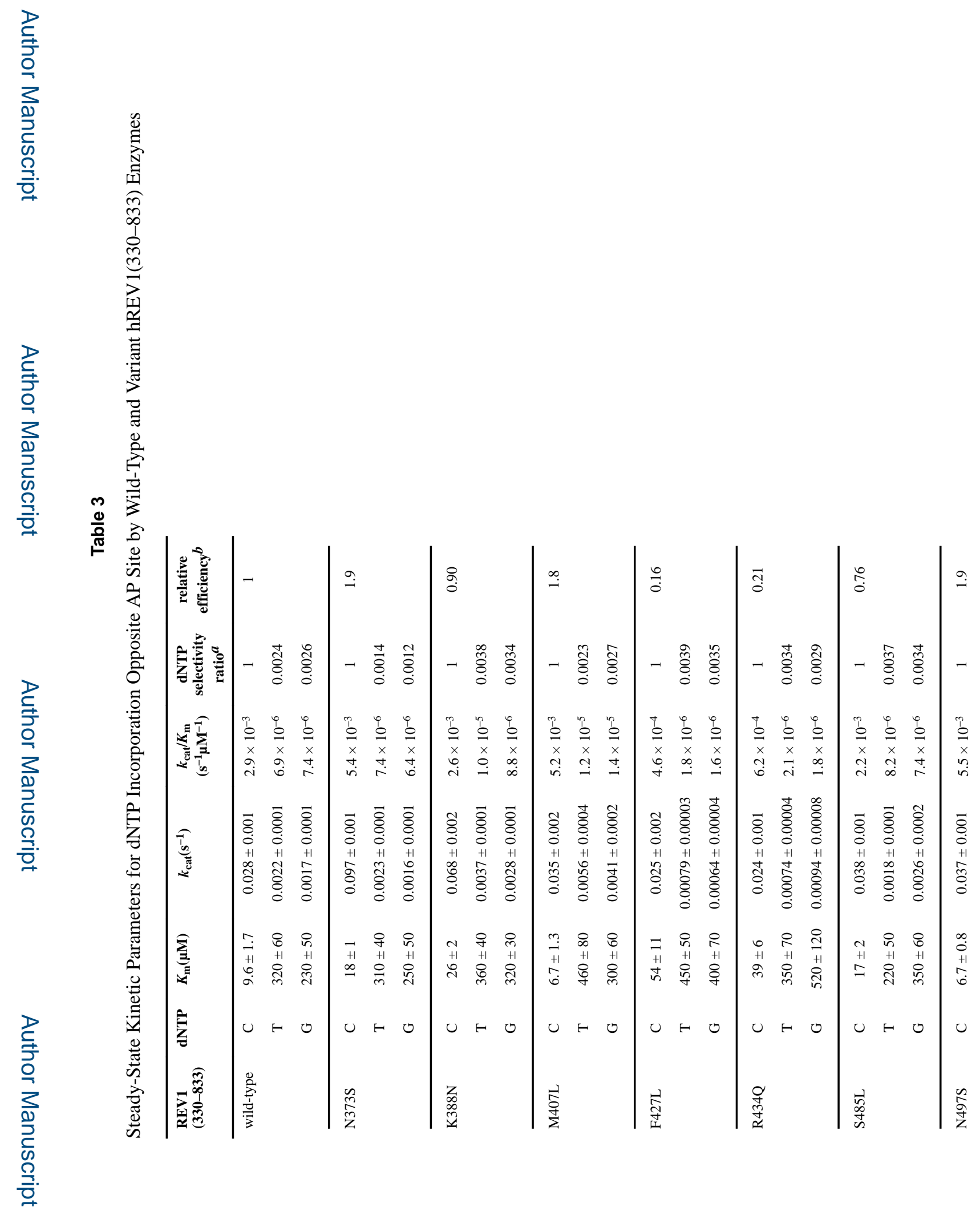

Chem Res Toxicol. Author manuscript; available in PMC 2017 March 21. 


\section{를 \\ ᄅ্}

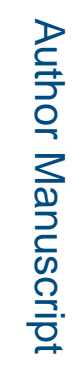

3

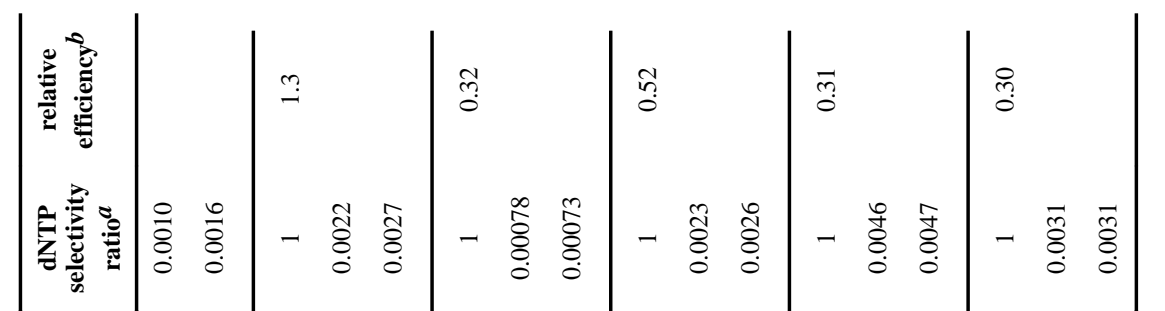

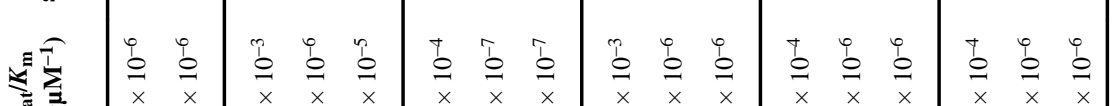

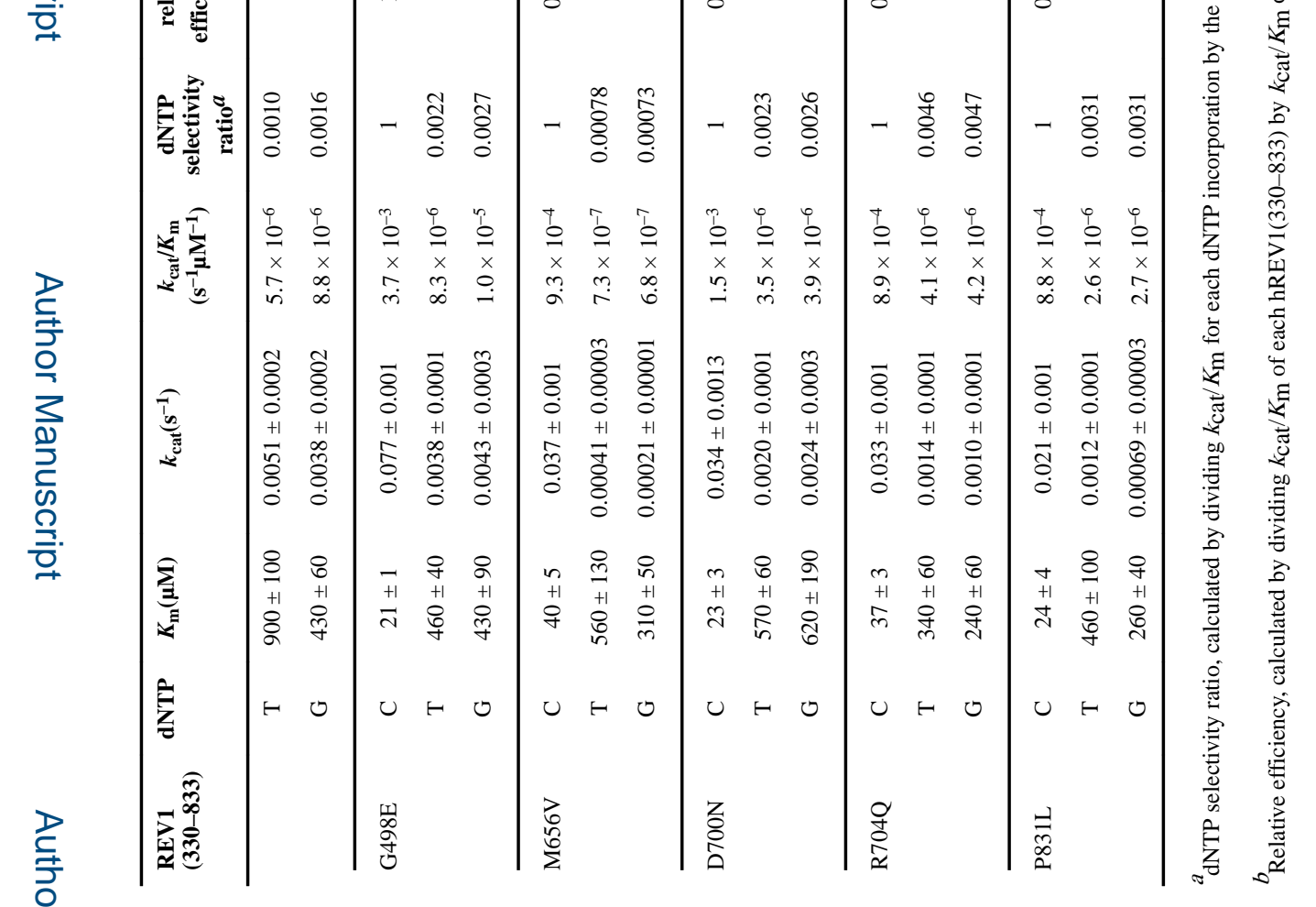




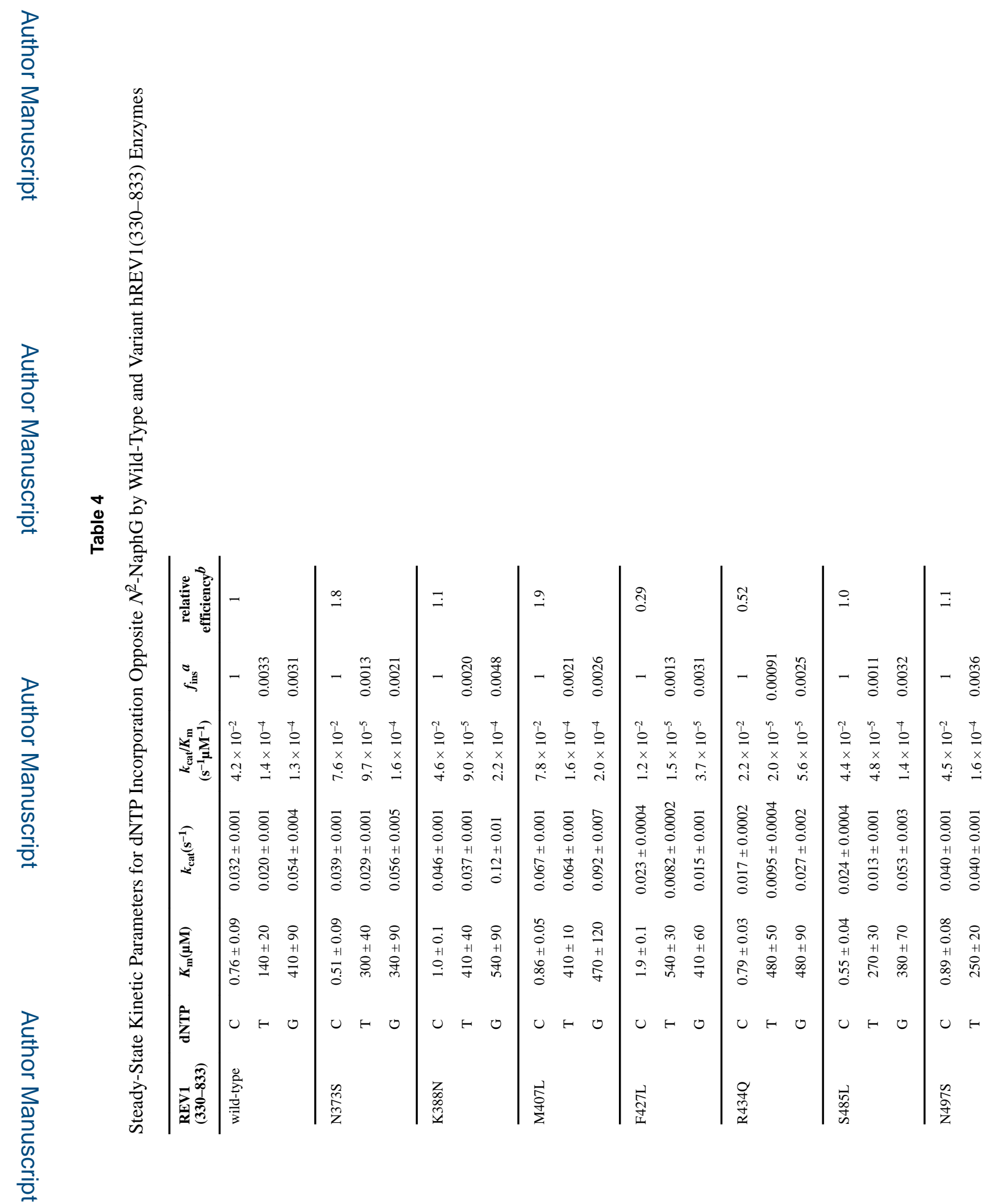

Chem Res Toxicol. Author manuscript; available in PMC 2017 March 21. 


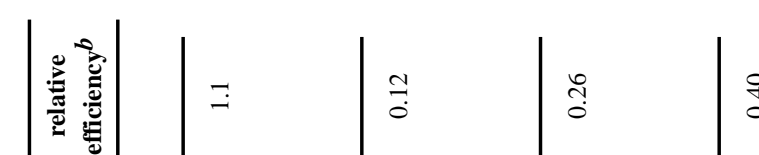

(2)

交$$
\text { }
$$

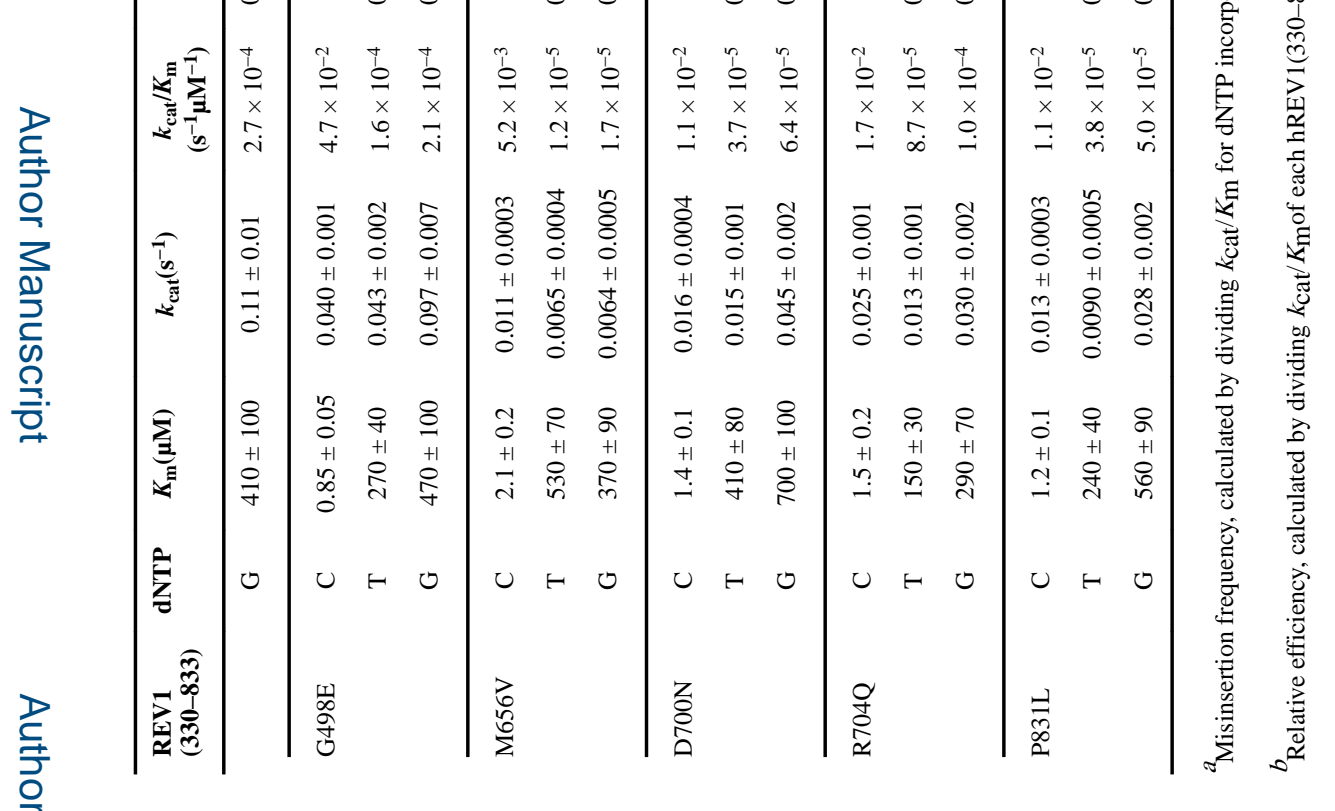$$
\text { 啇 }
$$ 


\section{Table 5}

Equilibrium Dissociation Constants $\left(K_{\mathrm{d}}\right)$ of Wild-Type and Variant hREV1(330-833) Enzymes for Four Different DNA Substrates

\begin{tabular}{ccccc}
\hline & \multicolumn{4}{c}{$K_{\mathbf{d}}(\mathbf{n M})$} \\
\cline { 2 - 5 } REV1(330-833) & $\begin{array}{c}\text { 18-FAM-mer/36- } \\
\text { G-mer }\end{array}$ & $\begin{array}{c}\text { 18-FAM-mer/36- } \\
\text { AP-mer }\end{array}$ & $\begin{array}{c}\text { 18-FAM-mer/36- } \\
\boldsymbol{N}^{2} \text {-NaphG-mer }\end{array}$ & $\begin{array}{c}\text { 11-mer/28-FAM- } \\
\text { G4-mer }\end{array}$ \\
\hline wild-type & $39 \pm 9$ & $41 \pm 7$ & $29 \pm 6$ & $4.7 \pm 0.6$ \\
N373S & $25 \pm 6$ & $25 \pm 6$ & $21 \pm 4$ & $1.8 \pm 0.6$ \\
K388N & $45 \pm 12$ & $54 \pm 12$ & $34 \pm 10$ & $3.3 \pm 1.0$ \\
M407L & $52 \pm 8$ & $41 \pm 13$ & $30 \pm 7$ & $5.3 \pm 1.8$ \\
F427L & $110 \pm 20$ & $120 \pm 20$ & $48 \pm 11$ & $3.7 \pm 0.8$ \\
R434Q & $77 \pm 18$ & $82 \pm 11$ & $56 \pm 13$ & $4.0 \pm 1.0$ \\
S485L & $35 \pm 11$ & $48 \pm 10$ & $29 \pm 7$ & $4.9 \pm 1.0$ \\
N497S & $25 \pm 5$ & $29 \pm 9$ & $23 \pm 4$ & $6.9 \pm 2.3$ \\
G498E & $22 \pm 6$ & $47 \pm 11$ & $16 \pm 5$ & $6.5 \pm 1.7$ \\
M656V & $100 \pm 30$ & $110 \pm 20$ & $42 \pm 11$ & $4.0 \pm 0.7$ \\
D700N & $49 \pm 15$ & $75 \pm 13$ & $30 \pm 8$ & $3.0 \pm 0.9$ \\
R704Q & $96 \pm 16$ & $89 \pm 13$ & $51 \pm 11$ & $4.3 \pm 0.6$ \\
P831L & $52 \pm 18$ & $130 \pm 20$ & $32 \pm 10$ & $4.1 \pm 1.5$ \\
\hline
\end{tabular}

Chem Res Toxicol. Author manuscript; available in PMC 2017 March 21. 


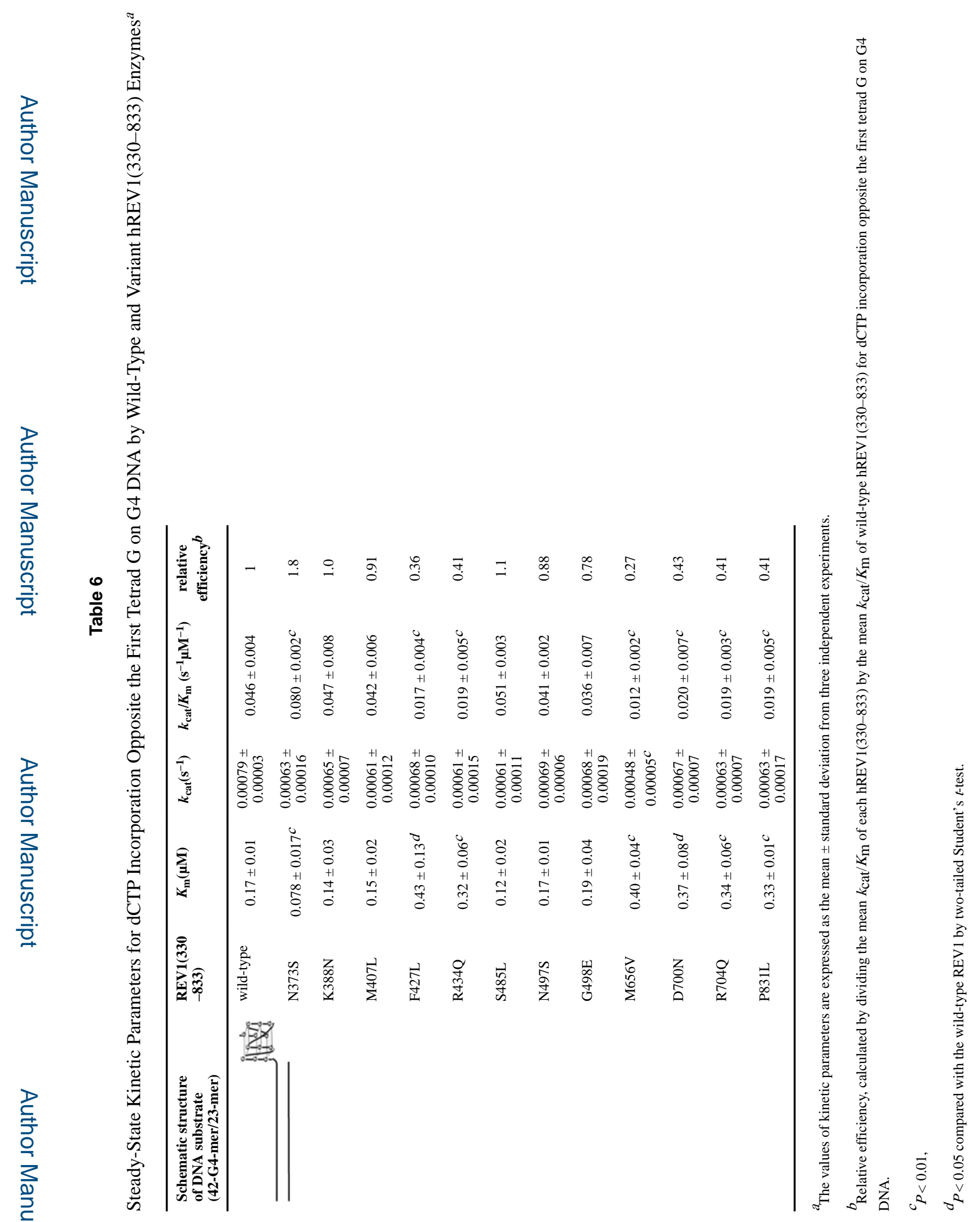

Chem Res Toxicol. Author manuscript; available in PMC 2017 March 21. 